\title{
Comparison of working fluids and cycle optimization for heat recovery ORCs from large internal combustion engines \\ Roberto Scaccabarozzi ${ }^{\text {a }}$, Michele Tavano ${ }^{\text {a }}$, Costante Mario Invernizzi ${ }^{\text {b }}$, Emanuele Martelli ${ }^{\mathrm{a},}{ }^{*}$ \\ a Dipartimento di Energia, Politecnico di Milano, Via Lambruschini 4, Milano, Italy \\ b Dipartimento di Ingegneria Meccanica e Industriale, Università degli Studi di Brescia, Via Branze 38, Brescia, Italy
}

\section{ABSTRACT}

This paper addresses the optimal working fluid selection for organic Rankine cycle recovering heat from heavy-duty internal combustion engines. Four cases are considered featuring two different engine exhaust temperatures $\left(245^{\circ} \mathrm{C}\right.$ vs $354^{\circ} \mathrm{C}$ ) and two scenarios (maximum recovery of mechanical power vs. cogeneration of low-temperature heat). The analysis includes both pure fluids, including recently synthesized refrigerants, and binary mixtures. To perform a fair comparison between the different fluids, a computationally efficient cycle optimization approach, able to determine the maximum achievable efficiency for each working fluid, is adopted. The approach combines the evolutionary optimization al-gorithm PGS-COM with a rigorous heat integration methodology. The most efficient fluids are HCFO-1233zde, HFE-245fa2, HFO-1336mzz, HFE-347mcc, HFE-245cb2 and Novec 649 for the engine with lower temperature exhausts (reaching an ORC mechanical efficiency of 18.6-19.9\%), and cyclopentane, ammonia, HCFO-1233zde, HFE-245fa2, HFO-1366mzz for the engine with higher temperature (reaching 23.76-22.70\% efficiency). Compared to pure fluids, the use of optimized binary mixtures does not appear to lead a considerable efficiency gain.

\section{Introduction}

Internal combustion engines (ICEs) play a significant role both in the industry (e.g., combined heat and power plants) and in transport. Improving their efficiency can cause a considerable reduction of primary energy consumption and environmental impact. Considering that, an ICE typically wastes around $50-60 \%$ of the input thermal power as medium-low temperature heat, the useful recovery of this energy and its efficient conversion into mechanical output could lead to a step change in the overall conversion efficiency. Among the possible heat recovery technologies, organic Rankine cycle (ORC) appears to be the most promising one [1]. Such option has been object of several thermodynamic and technoeconomic studies, as reported in the following.

Vaja et al. [2] analyze the possibility of recovering the heat available in flue gases and cooling water with three kinds of working fluids, hydrocarbons (Benzene), chlorofluorocarbon (CFC11), and hydrofluorocarbons (HFC-134a). The authors consider

\footnotetext{
* Corresponding author.

E-mail address: emanuele.martelli@polimi.it (E. Martelli).
}

three cycle configurations, a simple cycle, a pre-heated scheme that also recovers the cooling water thermal power and a regenerative solution, only for the dry fluid (Benzene). The authors report a relative increase of the efficiency between $4.8 \%$ and $12.8 \%$ cooling down the hot gases generated by a $3 \mathrm{MW}$ engine from $470{ }^{\circ} \mathrm{C}$ to $120^{\circ} \mathrm{C}$. They identify Benzene as the most promising fluid coupled with a regenerative cycle. The working fluid with higher critical temperature seems to take more advantages from the hightemperature heat source made available by the engine.

Wang et al. [3] investigate the improvements of a dual loop organic Rankine cycle (ORC) on an automotive diesel engine. They select HFC-134a to recover the low-temperature heat made available by the intercooler of the turbocharger, the cooling water system and the condenser of the high-temperature cycle, while HFC$245 \mathrm{fa}$ for a high-temperature ORC recovering the flue gases heat. They report an absolute increase in the overall system efficiency (ICE + ORC) of 8 percentage points and a power output increase of $26.63 \%$. On the other hand, when the engine operates at high speed and low load (highway conditions) the improvement is more remarkable with a power output rise between $53 \%$ and $72 \%$.

Ma et al. [4] consider a large naval engine with a mechanical power output of $46 \mathrm{MW}$. Considering that in several cases the 


\section{Nomenclature}

$\begin{array}{ll}\text { ALT } & \text { Atmospheric Lifetime } \\ \text { CFC } & \text { Chloro Fluoro Carbons } \\ \text { FC } & \text { Fluoro Carbons } \\ \text { GSS } & \text { Generating Set Search } \\ \text { GWP } & \text { Global Warming Potential } \\ \text { HCFC } & \text { Hydro Chloro Fluoro Carbons } \\ \text { HCFO } & \text { Hydro Chloro Fluoro Olefins } \\ \text { HFC } & \text { Hydro Fluoro Carbons } \\ \text { HFE } & \text { Hydro Fluoro Ethers } \\ \text { HFO } & \text { Hydro Fluoro Olefins } \\ \text { ICE } & \text { Internal Combustion Engine } \\ \text { LHV } & \text { Lower Heating Value } \\ \text { ODP } & \text { Ozone Depletion Potential } \\ \text { ORC } & \text { Organic Rankine Cycle } \\ \text { PGS-COM Particle Generating Set - Complex algorithm } \\ \text { PSO } & \text { Particle Swarm Optimizer } \\ \text { VLE } & \text { Vapor Liquid Equilibrium }\end{array}$

thermal power of the flue gases is already recovered on board with a water loop to satisfy the heating services, they propose to couple the system with a steam cycle to improve the overall efficiency. These kinds of applications operate with small load variation increasing the techno-economic feasibility of the additional investment of the solution. The authors report an increase of the system efficiency of 5.3 percentage points consequent of an additional power production of $5 \mathrm{MW}$ with an optimal evaporating pressure of 8 bar.

Kalikatzarakis et al. [5] perform a techno-economic optimization of an organic Rankine cycle coupled with a marine engine characterized by a power output of 72 MW. They consider 21 working fluids and three different cycle configurations and identify as the most promising option a double loop configuration with HFC-413a and HFC-245fa or a mixture of HFC-245fa and HFC-365mfc.

Larsen et al. [6] analyze the four possible alternatives to reduce the fuel consumption of a ship coupling a marine engine, with a power output of $17 \mathrm{MW}$, with four solutions. They compare a Rankine steam cycle, a Kalina cycle, an organic Rankine cycle, using HFC-245ca as working fluid, and an exhaust gas powered turbine, which expand the flue gases that bypass the turbocharger turbine at high loads. Each solution is optimized, and the outcomes show that the ORC case produces the highest power production improvement corresponding to $7 \%$ of the engine output at $85 \%$ load (reference case studied). Furthermore, the organic Rankine cycle has the simplest configuration but, on the other hand, it has a hazardous working fluid, and it is a relatively untested solution. In a previous work, Larsen et al. [7] optimize the selection of the working fluid screening 109 compounds and testing different possible cycle configurations. The engine is a high-efficient twostroke machine with a relatively low temperature of the exhaust gas, $\left(284{ }^{\circ} \mathrm{C}\right)$ and a mechanical power output of $72 \mathrm{MW}$. The authors consider heat source temperatures ranging from $240{ }^{\circ} \mathrm{C}$ to $350{ }^{\circ} \mathrm{C}$ and show supercritical cycle configurations are advantageous for flue gases temperatures above $300{ }^{\circ} \mathrm{C}$. Even if no working fluid is able to satisfy all the selection criteria, HFC-245fa and FC-236ea are indicated as most promising options due to favorable safety-related properties and high efficiency (despite of the high environmental impact).

Hung et al. [8] point out that standard steam Rankine cycles are not suitable to recover waste heat at temperatures lower than
$370{ }^{\circ} \mathrm{C}$ neither from an economic nor from an efficiency point of view. The authors compare five different working fluids with a simple cycle configuration using a sensitivity analysis concerning the evaporating and condensing pressure and changing the turbine inlet temperature. The results show that Benzene is the best solution among those analyzed with a system thermal efficiency around $30 \%$ and that isentropic fluids are more suitable to recover low-temperature heat. The authors also point out that the efficiency depends on the fluid critical point temperature and pressure, and on the latent heat at the condensing pressure.

Shu et al. [9] select alkaline-based fluids for ORCs recovering heat from a small ( $240 \mathrm{~kW}$ ) ICE characterized by a flue gases temperature of $519{ }^{\circ} \mathrm{C}$. The analysis indicates that the best solutions from an efficiency point of view are complex molecules, such as Nonane, Decane, and cyclic Alkanes, like Cyclohexane and Cyclopentane. With these fluids, the ORC thermal efficiency is approximately $18 \%$. Cyclohexane and Cyclopentane appear as the best options not only for the thermodynamic output but also for the proper condensing and evaporating pressure, and low irreversibility. Finally, the researchers recognize that due to the flammable nature of the working fluid safety issue can occur and a thermal oil loop can be required to ensure a safe operation.

Roy et al. [10] compare HCFC-123 and HFC-134a as working fluids for heat recovery ORCs. They found out that the regenerative supercritical configuration of the system is optimal for both fluids. Among the two fluids, HCFC-123 produces the higher power output corresponding to a cycle efficiency above $18 \%$.

Di Battista et al. [11] and Shu et al. [12] show the possible thermodynamic advantage of zeotropic mixtures of hydrocarbons with refrigerants for waste heat recovery from ICEs. Indeed, the temperature glide occurring in evaporation and condensation of zeotropic mixtures can considerably improve the thermodynamic matching with the temperature profile of the engine flue gases and cooling water leading to possible efficiency improvements up to $11 \%$ net power increase.

Given its relevance for the performance, costs as well as safety and environmental issues, several authors have addressed the optimal selection of working fluids. The proposed fluid selection approaches can be classified in three groups:

- screening approaches: a set of candidate fluids is identified according to engineering criteria and, for each fluid, the cycle variables and configuration are optimized using numerical methods (see, e.g., [13]);

- computer-aided molecular design methods [14,15]: the molecule with the most favorable properties is automatically synthetized by tackling a challenging mixed integer nonlinear optimization problem which can include the cycle optimization problem;

- molecular targeting methods [16]: these methods aim at identifying simultaneously the properties of the ideal ("target") working fluid and the optimal cycle variables. Then, through an ad hoc procedure, the most similar real working fluids are identified.

For a thorough review of computer-aided fluid selection and ORC optimization approaches the reader is referred to respectively [17] and [18].

This paper performs a thorough screening of working fluids for ORCs with the goal of identifying the most promising options for heat recovery from large ICEs. Using thermodynamic and engineering fluid selection criteria, more than 40 fluids are identified as possible candidates and considered in the analysis. Besides conventional fluids with known thermochemical properties, we consider novel refrigerants (HFE, HCFO, HFO) and binary zeotropic 
mixtures in order to identify those to be considered for further experimental analysis (e.g., measures of vapor liquid equilibria, viscosity, thermal stability, etc.) and engineering studies (e.g., turbine, pump or heat exchanger design). Since performing a detailed techno-economic optimization of the ORC (including the engineering design of the turbine, pump and heat exchanger network $[19,20])$ for each fluid is clearly not practicable because of the required computational time, a computationally efficient and rigorous thermodynamic optimization approach is used. It optimizes for each fluid the heat integration with the available hot and cold streams as well as the cycle variables.

\section{Problem statement}

We considered two scenarios, which are typically encountered in marine propulsion sector, energy utility systems and industrial applications (see Fig. 1):

- case "MEC" in which the energy system (ICE + ORC) must only produce mechanical or electrical power,

- case "CHP" in which the energy system must generate both mechanical/electrical power and heat. The heating power is transferred to the end user (ship, buildings, etc.) with a stream of hot water, hot oil or steam. In this analysis, we assume a loop of hot water heated up from $60^{\circ} \mathrm{C}$ to $80^{\circ} \mathrm{C}$.

To assess the effects of the heat source temperature on the optimal fluid selection, cycle configuration and efficiency, we considered two Diesel engines with the same size but opposite features and considerably different exhaust gas temperatures (see Table 1):

- Man S60-MC6: two-stroke and 10.2 MW of power output (lower temperature case "LT"),

- Wärtsilä 46DF: four-stroke and $10.3 \mathrm{MW}$ of power output (higher temperature case "HT").

Thus, for the resulting four cases (i.e., LT-MEC, LT-CHP, HT-MEC, HT-CHP), the heat recovery ORC has been optimized. In particular, the following optimization problem has been tackled:

- given the set of hot streams made available by the internal combustion engine (i.e., heat sources),

- given the temperatures of the of hot water loop transferring heat to the heat user (only for CHP scenarios),

- given the temperatures of the cooling streams;
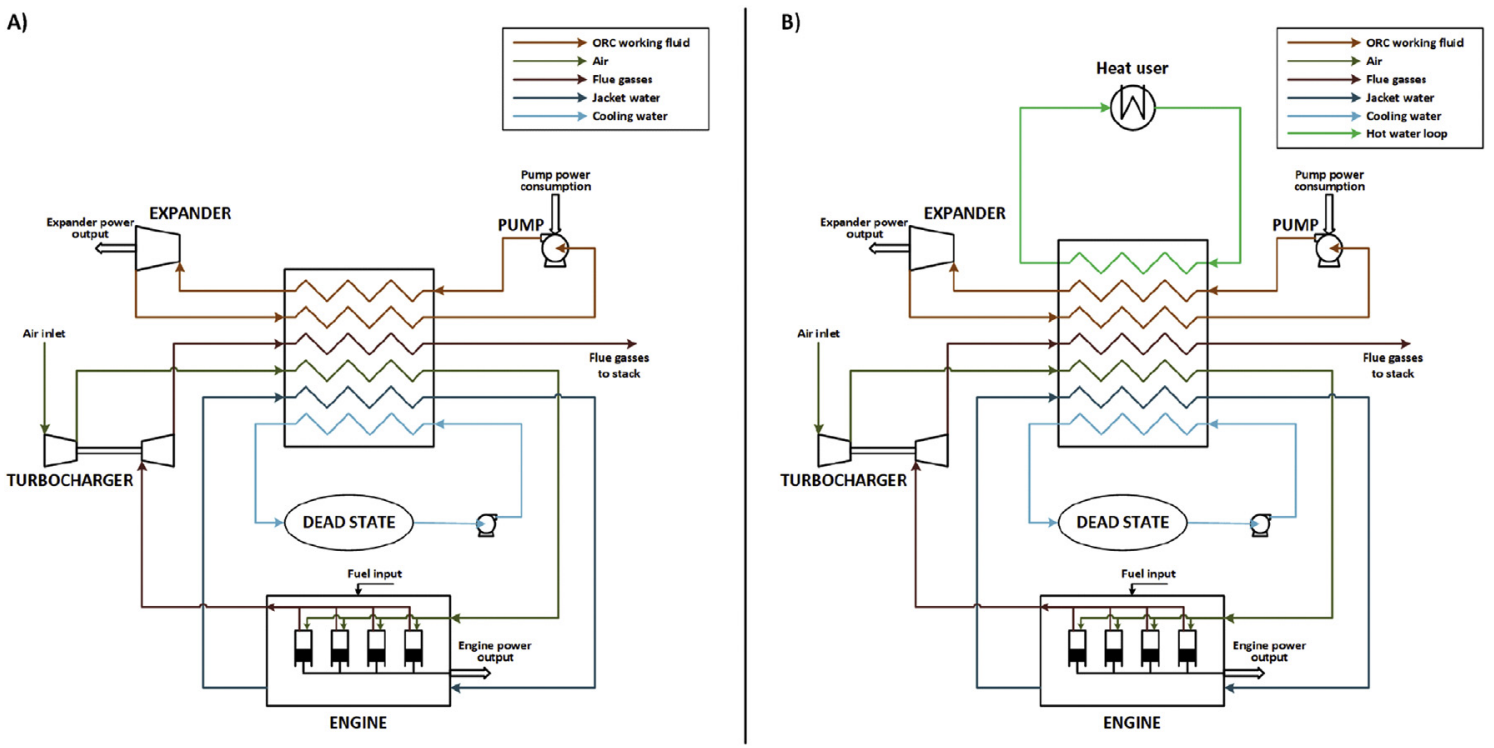

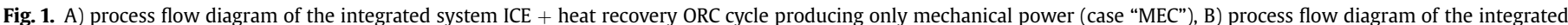
system ICE + heat recovery ORC cycle producing both mechanical and thermal power (case "CHP").

Table 1

Selected internal combustion engines characteristics (sources [21,22]).

\begin{tabular}{|c|c|c|c|c|}
\hline Flow & Feature & Units of measurement & Man S60-MC6 & Wärtsilä 46DF \\
\hline & Cycle type & - & Two-stroke & Four-stroke \\
\hline & Power output & $\mathrm{kW}$ & 10200 & 10305 \\
\hline & Efficiency (full load) & $\%$ & 49.59 & 45.33 \\
\hline \multirow[t]{3}{*}{ Exhaust gas } & Mass flow rate & $\mathrm{kg} / \mathrm{s}$ & 26.53 & 19.00 \\
\hline & Thermal power & $\mathrm{kW}$ & 3607 & 4892 \\
\hline & Temperature range & ${ }^{\circ} \mathrm{C}$ & $245-120$ & $354-120$ \\
\hline \multirow[t]{3}{*}{ Scavenge air } & Mass flow rate & $\mathrm{kg} / \mathrm{s}$ & 26.00 & 18.40 \\
\hline & Thermal power & $\mathrm{kW}$ & 3970 & 3789 \\
\hline & Temperature range & ${ }^{\circ} \mathrm{C}$ & $198-48$ & $253-50$ \\
\hline \multirow[t]{3}{*}{ Jacket water } & Mass flow rate & $\mathrm{kg} / \mathrm{s}$ & 21.06 & 23.16 \\
\hline & Thermal power & $\mathrm{kW}$ & 1490 & 1653 \\
\hline & Temperature range & ${ }^{\circ} \mathrm{C}$ & $80-63$ & $91-74$ \\
\hline
\end{tabular}


Table 2

Matrix of analyzed cases.

\begin{tabular}{lll}
\hline Scenarios & $\begin{array}{l}\text { Lower temperature flue } \\
\text { gases Man S60-MC6 }\end{array}$ & $\begin{array}{l}\text { Higher temperature flue } \\
\text { gases Wärtsilä 46DF }\end{array}$ \\
\hline $\begin{array}{c}\text { Mechanical power } \\
\text { output production } \\
\begin{array}{c}\text { Combined heat and } \\
\text { power production }\end{array}\end{array}$ & LT-MEC & HT-MEC \\
\hline
\end{tabular}

we aim at finding:

- the working fluid selection,

- the working fluid composition (only for mixtures),

- the ORC configuration (i.e., with/without regenerator, sub/supercritical, with/without superheating),

- the mass flow rate of working fluid that can be generated,

- the cycle variables (evaporating and condensing pressures, turbine inlet temperature, etc.);

which maximize the exergy efficiency of the ORC (see the definition in Subsections 2.1 and 2.2).

Since the objective of the work is to screen a large number of working fluids, the ideal Rankine cycle is considered in the assessment of the performance (i.e., isentropic pump and turbine, and heat exchangers without pressure drops and heat losses) so as to save computational time compared to more sophisticated models. Indeed, the performance of the equipment units strongly depend on the properties of the working fluid (i.e., molecular mass, molecular complexity, viscosity, etc. [23]) so it is not correct to assume the same efficiency figures for each fluid. However, the proper assessment of the performance requires detailed models of the equipment units (e.g., stage-by-stage [23], one-dimensional [24], etc.) which are too computationally expensive for the large number of fluids considered in this work.

Although equipment units were assumed to be ideal in terms of performance, the following constraints have been considered to guarantee the technical feasibility of the solutions:

- minimum vapor fraction of the flow evolving in the expander equal to 0.88 ,

- minimum allowed temperature difference in the heat exchangers equal to $5^{\circ} \mathrm{C}$,

- minimum condensation pressure equal to $0.03 \mathrm{bar}$,

- minimum superheating degree at the boiler outlet equal to $1^{\circ} \mathrm{C}$.

The lower bound on the condensation pressure is representative of the limit for currently available vacuum and sealing systems of steam condensers, while the minimum superheating degree of $1^{\circ} \mathrm{C}$ at the exit of the boiler guarantees that no liquid droplets can enter the turbine. In future works, the cycles of the most promising fluids will be re-optimized with detailed turbine and heat exchanger models, like those used in Refs. [23,25] and [26-28].

\subsection{Objective function for the MEC scenarios}

For MEC scenarios, the objective function is to maximize the exergy efficiency of the ORC system defined as:

$$
\begin{aligned}
\eta_{\mathrm{EX}, \mathrm{ORC}} & =\frac{\dot{\mathrm{W}}_{\mathrm{NET}}}{\dot{\mathrm{EX}}_{\dot{\mathrm{Q}}, \mathrm{F}}+\dot{\mathrm{EX}}_{\mathrm{Q}, \mathrm{A}}+\dot{\mathrm{EX}}_{\dot{\mathrm{Q}}, \mathrm{JW}}} \\
& =\frac{\dot{\mathrm{W}}_{\mathrm{EXP}}-\dot{\mathrm{W}}_{\mathrm{PUMP}}-\dot{\mathrm{W}}_{\mathrm{CW}}}{\dot{\mathrm{Q}}_{\mathrm{F}}\left(1-\frac{\mathrm{T}_{0}}{\mathrm{~T}_{\mathrm{ML}, \mathrm{F}}}\right)+\dot{\mathrm{Q}}_{\mathrm{A}}\left(1-\frac{\mathrm{T}_{0}}{\mathrm{~T}_{\mathrm{ML}, \mathrm{A}}}\right)+\dot{\mathrm{Q}}_{\mathrm{JW}}\left(1-\frac{\mathrm{T}_{0}}{\mathrm{~T}_{\mathrm{ML}, \mathrm{JW}}}\right)}
\end{aligned}
$$

where $\eta_{E X, O R C}$ denotes the ORC system exergy efficiency, $\dot{W}_{N E T}$ is the net mechanical power generated by ORC while $E X_{\dot{Q}, F}, E X_{\dot{Q}, A}$, and $\dot{E} X_{\dot{Q} . J W}$ denote, respectively, the exergy (i.e., power which could be generated with a reversible engine) associated to the thermal power made available by the ICE flue gases, scavenger air and jacket water respectively. In the right hand side of Eq. (1), $\dot{W}_{E X P}$ denotes the mechanical power output of the expander, $\dot{W}_{\text {PUMP }}$ the mechanical power consumption of the cycle pump and $\dot{W}_{C W}$ the power consumption of the cooling water circulation pump. At the denominator, $\dot{Q}_{F}, \dot{Q}_{A}$, and $\dot{Q}_{J W}$ represent, respectively, the thermal power available in the flue gases, the scavenger air and the jacket water, and $T_{M L, F}, T_{M L, A}$, and $T_{M L J W}$ are the corresponding mean logarithmic temperatures [29]. Finally, $T_{0}$ denotes the dead state temperature (assumed equal to the minimum cooling water temperature, i.e., $10^{\circ} \mathrm{C}$ )

It is worth noting that maximizing the exergy efficiency of the ORC (as defined in Eqs. (1) and (5)) is equivalent to maximizing the

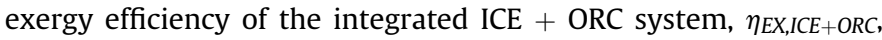
defined in Eq. (2):

$\eta_{\text {EX,ICE }+ \text { ORC }}=\frac{\dot{\mathrm{W}}_{\text {ICE }}+\dot{\mathrm{W}}_{\mathrm{EXP}}-\dot{\mathrm{W}}_{\mathrm{PUMP}}-\dot{\mathrm{W}}_{\mathrm{CW}}}{\dot{E X}_{\mathrm{FUEL}}}$

where $\dot{W}_{I C E}$ denotes the mechanical power generated by the ICE and $E X_{F U E L}$ is the exergy of the engine fuel.

Besides, for MEC scenarios, maximizing the exergy efficiency

defined in Eq. (1) corresponds to maximizing the net mechanical

power generated by the ORC $\left(\dot{W}_{N E T}\right)$, the net mechanical efficiency of the ORC $\left(\eta_{M E C, O R C}\right)$ and the mechanical efficiency of the overall system $\left(\eta_{M E C, I C E+O R C}\right)$ comprising the ICE and the ORC:

$\eta_{\mathrm{MEC}, \mathrm{ORC}}=\frac{\dot{\mathrm{W}}_{\mathrm{EXP}}-\dot{\mathrm{W}}_{\mathrm{PUMP}}-\dot{\mathrm{W}}_{\mathrm{CW}}}{\dot{\mathrm{Q}}_{\mathrm{AV}}}$

$\eta_{\mathrm{MEC}, \mathrm{ICE}+\mathrm{ORC}}=\frac{\dot{\mathrm{W}}_{\mathrm{ICE}}+\dot{\mathrm{W}}_{\mathrm{EXP}}-\dot{\mathrm{W}}_{\mathrm{PUMP}}-\dot{\mathrm{W}}_{\mathrm{CW}}}{\dot{\mathrm{m}}_{\mathrm{FUEL}} \mathrm{LHV}}$

where $\dot{Q}_{A V}$ is the total available thermal power of the hot engine streams, $\dot{m}_{F U E L}$ and $L H V$ are the mass flow rate and lower heating value of the engine fuel respectively.

\subsection{Objective function for the CHP scenarios}

For the CHP scenarios, the objective function of the cycle optimization problems is to maximize the exergy efficiency of the CHP ORC system defined as:

$$
\begin{aligned}
\eta_{\mathrm{EX}, \mathrm{ORC}}= & \frac{\dot{\mathrm{W}}_{\mathrm{NET}}+\dot{\mathrm{EX}}_{\dot{\mathrm{Q}}, \mathrm{HU}}}{\dot{\mathrm{EX}}_{\dot{\mathrm{Q}}, \mathrm{F}}+\dot{\mathrm{EX}}_{\dot{\mathrm{Q}, \mathrm{A}}}+\dot{\mathrm{EX}}_{\dot{\mathrm{Q}}, \mathrm{JW}}} \\
= & \frac{\dot{\mathrm{W}}_{\mathrm{EXP}}-\dot{\mathrm{W}}_{\mathrm{PUMP}}+\dot{\mathrm{Q}}_{\mathrm{HU}}\left(1-\frac{\mathrm{T}_{0}}{\mathrm{~T}_{\mathrm{ML}, \mathrm{HU}}}\right)-\dot{\mathrm{W}}_{\mathrm{CW}}}{\dot{\mathrm{Q}}_{\mathrm{F}}\left(1-\frac{\mathrm{T}_{0}}{\mathrm{~T}_{\mathrm{ML}, \mathrm{F}}}\right)+\dot{\mathrm{Q}}_{\mathrm{A}}\left(1-\frac{\mathrm{T}_{0}}{\mathrm{~T}_{\mathrm{ML}, \mathrm{A}}}\right)+\dot{\mathrm{Q}}_{\mathrm{JW}}\left(1-\frac{\mathrm{T}_{0}}{\mathrm{~T}_{\mathrm{ML}, \mathrm{JW}}}\right)}
\end{aligned}
$$

where, in addition to the terms of Eq. (1), $\dot{X X}_{\dot{Q} . H U}, \dot{Q}_{H U}$, and $T_{M L, H U}$ denote the respectively the exergy flow, the thermal power, and the mean temperature of the water loop used to provide heat to the heat user.

In CHP scenarios, also the thermal power delivered to the heat user has a positive value which, from a thermodynamic point of view, corresponds to the efficiency of a Lorentz cycle $\left(\eta_{H U}\right)$ 
operating between the hot water temperatures and the dead state:

$\eta_{\mathrm{HU}}=\left(1-\frac{\mathrm{T}_{0}}{\mathrm{~T}_{\mathrm{ML}, \mathrm{HU}}}\right)$

In this way, the excess heat, which cannot be efficiently converted into mechanical power by the ORC, can be used to heat up the hot water loop for the heat user. If the condensation temperature is set to values sufficiently higher than the hot water for the heat user, also the condensation heat of the ORC can be exploited to generate useful thermal power. In such case, the ORC features a socalled "back-pressure" CHP configuration. The optimization methodology presented in the next section allows determining whether or not it is advantageous for the exergy efficiency to adopt the back-pressure configuration or the standard one while taking into ac-count the cycle performance as well as the heat integration between hot, cold and cycle streams.

Since the study is not focusing on a specific application (i.e., industry requiring a certain amount of heat), but a general screening to identify the 3-4 most promising working fluids, fixing an arbitrary value of required thermal power could penalize certain working fluids and favoring others without any technical reason, leading to an unfair comparison. Thus, the choice of optimizing also the cogenerated thermal power allows considering the best heat integration solution for each fluid leading to a fair comparison, i.e., not influenced by arbitrary assumptions.

It is important to note that maximizing $\eta_{E X}$ is equivalent to maximize the exergy efficiency of the overall CHP system (ICE + ORC), as defined in Eq. (7):

$\eta_{\mathrm{EX}, \mathrm{ICE}+\mathrm{ORC}}=\frac{\dot{\mathrm{W}}_{\mathrm{ICE}}+\dot{\mathrm{W}}_{\mathrm{EXP}}-\dot{\mathrm{W}}_{\mathrm{PUMP}}+\dot{\mathrm{Q}}_{\mathrm{HU}}\left(1-\frac{\mathrm{T}_{0}}{\mathrm{~T}_{\mathrm{ML}, \mathrm{HU}}}\right)-\dot{\mathrm{W}}_{\mathrm{CW}}}{\mathrm{EX}_{\mathrm{FUEL}}}$

For CHP scenarios, since the thermal power given to the heat user $\left(\dot{Q}_{H U}\right)$ is a useful output, also the thermal efficiency of the ORC $\left(\eta_{T H, O R C}\right)$ and overall system $\left(\eta_{T H, I C E+O R C}\right)$ are relevant performance indexes:

$\eta_{\mathrm{TH}, \mathrm{ORC}}=\frac{\dot{\mathrm{Q}}_{\mathrm{HU}}}{\dot{\mathrm{Q}}_{\mathrm{AV}}}$

$\eta_{\mathrm{TH}, \mathrm{ICE}+\mathrm{ORC}}=\frac{\dot{\mathrm{Q}}_{\mathrm{HU}}}{\dot{\mathrm{m}}_{\mathrm{FUEL}} \mathrm{LHV}}$

\section{Methodology}

Among all the available fluids, we identified a subset of promising ones, both pure fluids and binary mixtures, according to simple selection criteria (see Section 3.1). Then, for each selected working fluid, the cycle configuration and the cycle variables have been optimized with the algorithm described in Section 3.2.1. The heat integration between hot and cold streams (including the ORC streams) is optimized using the energy targeting method described in Section 3.2.2. For each case, we ranked the working fluids according to the exergy efficiency of the optimized ORC and discussed their relevant properties (environmental impact, toxicity, flammability, thermochemical stability, etc.) so as to identify the most promising ones to be considered in future works.

\subsection{Fluid selection}

The final goal of this work is to identify working fluids which yield to optimal or close-to-optimal thermodynamic performance (i.e., exergy efficiency) without excessive costs and with limited (possibly zero) safety and environmental concerns. For this reason, we considered the following criteria in the selection of the pure fluids:

1) good thermodynamic matching with the available heat sources (i.e., hot streams made available by the internal combustion engine) and heat sinks (i.e., cooling water and hot water for the heat user). To this end, several authors (e.g., [2,30,31]) have observed that the critical temperature has a significant impact on the ORC efficiency and that the maximum efficiency is achieved for fluids featuring a critical temperature approximately $88-92 \%$ of the hot stream temperature. Thus, we selected pure fluids featuring a critical temperature lower than the engine flue gas temperature,

2) condensation pressure at the cooling water temperature (for the MEC scenario) or hot water temperature (for the CHP scenario) higher or equal to 0.03 bar. This criterion excludes working fluids that would require too expensive vacuum and sealing systems for the condenser,

3) limited environmental impact. To evaluate this aspect, we used three parameters, the ozone depletion potential (ODP), the atmospheric lifetime (ALT), and the global warming potential (GWP). We restricted the analysis to working fluids with zero ODP, and in the final ranking of the fluids, we favor fluids with low GWP, non-toxic, and non-corrosive,

4) known thermodynamic properties (i.e., specific volume, saturation temperatures/pressures, enthalpy, entropy). We considered fluids whose thermodynamic properties have been measured and accurate models are available in the REFPROP v9.1 [32,33] database,

5) thermochemical stability, i.e., capability to preserve unchanged the fluid composition and the main physical properties, up to $200{ }^{\circ} \mathrm{C}$ for the Man S60-MC6 engine and $300{ }^{\circ} \mathrm{C}$ for the Wärtsilä 46DF. However, thermochemical stability data are available only for well-known fluids and a limited range of temperatures. For novel pure fluids and mixtures, like some of those considered in this work, no stability data are available in the literature and long and expensive test campaigns should be performed using ad hoc facilities (e.g., [31, 34]). For those fluids with known thermochemical stability properties, the relevant references are reported in Table 3 and Table 4 As far as the thermal stability of fluids is concerned, we made an extensive literature search finding data for a limited number of fluids. The most relevant references are reported in the last column of Tables 3 and 4 . In particular, we found useful references for the following fluids:

1) ammonia-water mixtures which are operated in Kalina cycles up to $500^{\circ} \mathrm{C}$ [36],

2) Novec 649 which is claimed to be thermally stable up to $300^{\circ} \mathrm{C}$ [40],

3) HFO-1336mzz stable up to $250{ }^{\circ} \mathrm{C}$ [41],

4) aentane and cycle-pentane, thermally stable up to $300{ }^{\circ} \mathrm{C}$ and toluene stable up to $350{ }^{\circ} \mathrm{C}[39,42]$,

5) methanol, which does not show decomposition up to $330^{\circ} \mathrm{C}$ [43],

6) siloxanes (MM, MDM, D4) stable up to $300-350^{\circ} \mathrm{C}[39,44]$,

7) dimethyl ether, likely stable above $300{ }^{\circ} \mathrm{C}$ [35]. Unfortunately, no thermal stability data were found for the

novel refrigerants HCFO-1233zde, HFO-1234zez, and HFC-365mfc, 
Table 3

Pure fluids selected for the Man S60-MC6 engine featuring lower temperature flue gases.

\begin{tabular}{|c|c|c|c|c|c|c|c|c|c|}
\hline Class & Name & Chemical formula & Exp. type & $\mathrm{MM}[\mathrm{kg} / \mathrm{kmol}]$ & $\mathrm{p}_{\mathrm{cr}}[\mathrm{bar}]$ & $\mathrm{T}_{\mathrm{cr}}\left[{ }^{\circ} \mathrm{C}\right]$ & GWP 100ys & ALT [year] & Thermo-chemical stability \\
\hline $\mathrm{HC}$ & Cyclopropane & $\mathrm{C}_{3} \mathrm{H}_{6}$ & Wet & 42.08 & 55.8 & 125.15 & $<20$ & 0.44 & \\
\hline Ether & Dimethyl ether & $\mathrm{C}_{2} \mathrm{H}_{6} \mathrm{O}$ & Wet & 46.07 & 53.37 & 127.23 & 1 & 15.00 & [35] \\
\hline Inorganic & Ammonia & $\mathrm{NH}_{3}$ & Wet & 17.03 & 113.33 & 132.25 & 0 & 0.02 & [36] \\
\hline HFE & HFE-245cb2 & $\mathrm{C}_{3} \mathrm{H}_{3} \mathrm{~F}_{5} \mathrm{O}$ & Dry & 150.05 & 28.86 & 133.66 & 654 & 4.90 & [37] \\
\hline $\mathrm{HC}$ & Isobutane & $\mathrm{C}_{4} \mathrm{H}_{10}$ & Ise & 58.12 & 36.29 & 134.66 & $<20$ & 16.00 & \\
\hline $\mathrm{HC}$ & Isobutene & $\mathrm{C}_{4} \mathrm{H}_{8}$ & Ise & 56.11 & 40.1 & 144.94 & n.a. & n.a. & \\
\hline $\mathrm{HC}$ & Butene & $\mathrm{C}_{4} \mathrm{H}_{8}$ & Ise & 56.11 & 40.05 & 146.14 & n.a. & n.a. & \\
\hline HFO & HFO-1234zez & $\mathrm{C}_{3} \mathrm{H}_{2} \mathrm{~F}_{4}$ & Ise & 114.04 & 35.33 & 150.12 & 1 & 0.04 & \\
\hline $\mathrm{HC}$ & Butane & $\mathrm{C}_{4} \mathrm{H}_{10}$ & Ise & 58.12 & 37.96 & 151.98 & $<20$ & 18.00 & \\
\hline HFC & HFC-245fa & $\mathrm{C}_{3} \mathrm{H}_{3} \mathrm{~F}_{5}$ & Ise & 134.05 & 36.51 & 154.01 & 858 & 7.70 & {$[38,39]$} \\
\hline $\mathrm{HC}$ & trans-Butene & $\mathrm{C}_{4} \mathrm{H}_{8}$ & Ise & 56.11 & 40.27 & 155.46 & n.a. & n.a. & \\
\hline $\mathrm{HC}$ & Neopentane & $\mathrm{C}_{5} \mathrm{H}_{12}$ & Dry & 72.15 & 31.96 & 160.59 & n.a. & n.a. & \\
\hline $\mathrm{HC}$ & cis-Butene & $\mathrm{C}_{4} \mathrm{H}_{8}$ & Ise & 56.11 & 42.26 & 162.60 & n.a. & n.a. & \\
\hline HFE & HFE-347mcc & $\mathrm{C}_{4} \mathrm{H}_{3} \mathrm{~F}_{7} \mathrm{O}$ & Dry & 200.05 & 24.76 & 164.55 & 530 & 5.00 & \\
\hline HCFO & HCFO-1233zde & $\mathrm{C}_{3} \mathrm{H}_{2} \mathrm{ClF}_{3}$ & Ise & 130.5 & 36.24 & 166.45 & 1 & 0.07 & \\
\hline Fluoroketone & Novec 649 & $\mathrm{C}_{6} \mathrm{~F}_{12} \mathrm{O}$ & Dry & 316.04 & 18.69 & 168.66 & 1 & 14.00 & {$[40]$} \\
\hline HFO & HFO-1336mzz & $\mathrm{C}_{4} \mathrm{H}_{2} \mathrm{~F}_{6}$ & Dry & 164.06 & 29.01 & 171.27 & 2 & 0.06 & [41] \\
\hline HFE & HFE-245fa2 & $\mathrm{C}_{3} \mathrm{H}_{3} \mathrm{~F}_{5} \mathrm{O}$ & Dry & 150.05 & 34.33 & 171.73 & 812 & 5.50 & \\
\hline HFC & HFC-245ca & $\mathrm{C}_{3} \mathrm{H}_{3} \mathrm{~F}_{5}$ & Dry & 134.05 & 39.41 & 174.42 & 716 & 6.50 & {$[38,39]$} \\
\hline HFC & HFC-365mfc & $\mathrm{C}_{4} \mathrm{H}_{5} \mathrm{~F}_{5}$ & Dry & 148.07 & 32.66 & 186.85 & 804 & 8.70 & [38] \\
\hline $\mathrm{HC}$ & Isopentane & $\mathrm{C}_{5} \mathrm{H}_{12}$ & Dry & 72.15 & 33.78 & 187.2 & $<20$ & 9.00 & \\
\hline $\mathrm{HC}$ & Pentane & $\mathrm{C}_{5} \mathrm{H}_{12}$ & Dry & 72.15 & 33.7 & 196.55 & $<20$ & 9.00 & {$[39,42]$} \\
\hline Inorganic & Water & $\mathrm{H}_{2} \mathrm{O}$ & Wet & 18.02 & 220.64 & 373.95 & 0 & 0.00 & \\
\hline
\end{tabular}

and for Dimethyl carbonate and Methylcyclohexane. As far as HFE-347mcc and HFE-245fa2 are concerned, their stability should reasonably reach $300{ }^{\circ} \mathrm{C}$ on the basis of the experimental results obtained by Invernizzi and Pasini [37] for another HFE fluid (HFE-7100). Similarly, hydrocarbons (i.e., isopentane, isohexane, hexane, heptane, isooctane, cyclohexane, isobutane, isobutene, butene, butane, trans-butene, neopentane, cis-butene, and cyclopropane) are assumed thermally stable up to about $300{ }^{\circ} \mathrm{C}$ on the basis of the tests performed on pentane, cyclopentane and toluene. Fluids with unknown thermal stability have been kept in the analysis with the goal of guiding future experimental campaigns: if such fluids turn out to be very promising, future works may determine their fluid decomposition limit using the test rig available at the University of Brescia [31,34]. However, it is important to note that the results for the above-listed fluids with uncertain thermal stability limit could be misleading due to the too high operating temperature. The optimization of the cycle variables should be repeated after determining the fluid decomposition limit (setting this temperature as upper bound for the turbine inlet temperature).

As far as binary zeotropic mixtures are considered, in addition to the above-mentioned five criteria, we restricted the attention to mixtures with a temperature glide in condensation greater than $5{ }^{\circ} \mathrm{C}$. The temperature glide is evaluated by calculating the bubble and dew temperatures at several pressures in the range $0.5-5$ bar. This criterion aims at exploiting the advantage of mixtures compared to pure fluids. The temperature glide in evaporation has not been considered among the selection criteria since the optimal cycle is expected to be supercritical for many fluids (hence it may be

Table 4

Pure fluids selected for the Wärtsilä 46DF engine featuring higher temperature flue gases.

\begin{tabular}{|c|c|c|c|c|c|c|c|c|c|}
\hline Class & Name & Chemical formula & Exp. type & MM [kg/kmol] & $\mathrm{p}_{\mathrm{cr}}[\mathrm{bar}]$ & $\mathrm{T}_{\mathrm{cr}}\left[{ }^{\circ} \mathrm{C}\right]$ & GWP 100ys & ALT [years] & Thermo-chemical stability \\
\hline Inorganic & Ammonia & $\mathrm{NH}_{3}$ & Wet & 17.03 & 113.33 & 132.25 & 0 & 0.00 & [36] \\
\hline HFE & HFE-347mcc & $\mathrm{C}_{4} \mathrm{H}_{3} \mathrm{~F}_{7} \mathrm{O}$ & Dry & 200.05 & 24.76 & 164.55 & 530 & 5.00 & \\
\hline HCFO & HCFO-1233zde & $\mathrm{C}_{3} \mathrm{H}_{2} \mathrm{ClF}_{3}$ & Ise & 130.50 & 36.24 & 166.45 & 1 & 0.07 & \\
\hline Fluoroketone & Novec 649 & $\mathrm{C}_{6} \mathrm{~F}_{12} \mathrm{O}$ & Dry & 316.04 & 18.69 & 168.66 & 1 & 14.00 & [40] \\
\hline HFO & HFO-1336mzz & $\mathrm{C}_{4} \mathrm{H}_{2} \mathrm{~F}_{6}$ & Dry & 164.06 & 29.01 & 171.27 & 2 & 0.06 & [41] \\
\hline HFE & HFE-245fa2 & $\mathrm{C}_{3} \mathrm{H}_{3} \mathrm{~F}_{5} \mathrm{O}$ & Dry & 150.05 & 34.33 & 171.73 & 812 & 5.50 & \\
\hline HFC & HFC-245ca & $\mathrm{C}_{3} \mathrm{H}_{3} \mathrm{~F}_{5}$ & Dry & 134.05 & 39.41 & 174.42 & 716 & 6.50 & {$[38,39]$} \\
\hline HFC & HFC-365mfc & $\mathrm{C}_{4} \mathrm{H}_{5} \mathrm{~F}_{5}$ & Dry & 148.07 & 32.66 & 186.85 & 804 & 8.70 & \\
\hline $\mathrm{HC}$ & Isopentane & $\mathrm{C}_{5} \mathrm{H}_{12}$ & Dry & 72.15 & 33.78 & 187.20 & $<20$ & 9.00 & \\
\hline $\mathrm{HC}$ & Pentane & $\mathrm{C}_{5} \mathrm{H}_{12}$ & Dry & 72.15 & 33.70 & 196.55 & $<20$ & 9.00 & {$[39,42]$} \\
\hline $\mathrm{HC}$ & Isohexane & $\mathrm{C}_{6} \mathrm{H}_{14}$ & Dry & 86.18 & 30.40 & 224.55 & n.a. & n.a. & \\
\hline $\mathrm{HC}$ & Hexane & $\mathrm{C}_{6} \mathrm{H}_{14}$ & Dry & 86.18 & 30.34 & 234.67 & n.a. & n.a. & \\
\hline $\mathrm{HC}$ & Cyclopentane & $\mathrm{C}_{5} \mathrm{H}_{10}$ & Ise & 70.13 & 45.71 & 238.57 & $<11$ & n.a. & {$[39,42]$} \\
\hline Alcohol & Methanol & $\mathrm{CH}_{4} \mathrm{O}$ & Wet & 32.04 & 82.16 & 240.23 & 3 & n.a. & [43] \\
\hline Alcohol & Ethanol & $\mathrm{C}_{2} \mathrm{H}_{6} \mathrm{O}$ & Wet & 46.07 & 62.68 & 241.56 & n.a. & n.a. & \\
\hline Siloxane & MM & $\mathrm{C}_{6} \mathrm{H}_{18} \mathrm{OSi}_{2}$ & Dry & 162.38 & 19.39 & 245.55 & n.a. & n.a. & {$[39,44]$} \\
\hline $\mathrm{HC}$ & Heptane & $\mathrm{C}_{7} \mathrm{H}_{16}$ & Dry & 100.20 & 27.36 & 266.98 & n.a. & n.a. & \\
\hline $\mathrm{HC}$ & Isooctane & $\mathrm{C}_{8} \mathrm{H}_{18}$ & Dry & 114.23 & 25.72 & 270.85 & n.a. & n.a. & \\
\hline $\mathrm{HC}$ & Cyclohexane & $\mathrm{C}_{6} \mathrm{H}_{12}$ & Dry & 84.16 & 40.81 & 280.45 & n.a. & n.a. & \\
\hline Carbonate & Dimethyl carbonate & $\mathrm{C}_{3} \mathrm{H}_{6} \mathrm{O}_{3}$ & Dry & 90.08 & 49.09 & 283.85 & n.a. & n.a. & \\
\hline Siloxane & MDM & $\mathrm{C}_{8} \mathrm{H}_{24} \mathrm{O}_{2} \mathrm{Si}_{3}$ & Dry & 236.53 & 14.15 & 290.94 & n.a. & n.a. & {$[39,44]$} \\
\hline $\mathrm{HC}$ & Methylcyclohexane & $\mathrm{C}_{7} \mathrm{H}_{14}$ & Dry & 98.19 & 34.70 & 299.05 & n.a. & n.a. & \\
\hline Siloxane & D4 & $\mathrm{C}_{8} \mathrm{H}_{24} \mathrm{O}_{4} \mathrm{Si}_{4}$ & Dry & 296.62 & 13.32 & 313.34 & n.a. & n.a. & {$[39,44]$} \\
\hline $\mathrm{HC}$ & Toluene & $\mathrm{C}_{7} \mathrm{H}_{8}$ & Dry & 92.14 & 41.26 & 318.60 & 3 & n.a. & {$[39,42]$} \\
\hline Inorganic & Water & $\mathrm{H}_{2} \mathrm{O}$ & Wet & 18.02 & 220.64 & 373.95 & 0 & 0.00 & \\
\hline
\end{tabular}


useless from a thermodynamic point of view).

Since for novel mixtures (namely mixtures of refrigerants, hydrocarbons, and siloxanes) vapor liquid equilibrium (VLE) data are not available (to the best of the authors' knowledge), calibrated mixing parameters are not available in REFPROP yet. It is worth noting that, even if no data have been found on the miscibility of HCFO-1233zde with HFC-134a and HFO-1336mzz with HFC-134a, their miscibility is expected because of the positive results found for similar refrigerants in Ref. [45]. To estimate the thermodynamic properties (i.e., specific volume, dew/bubble temperatures, enthalpy, entropy) of these mixtures, REFPROP uses the predictive method proposed by Lemmon and McLinden [46].

It is important to note that flammable fluids have been included in the analysis for two reasons:

- according to previous studies (e.g., [1,2,7-9]), a considerable number of promising fluids for ORC recovering high-medium temperature heat are hydrocarbons,

- to prevent safety issues, it is possible to use an intermediate hot oil loop between the ICE flue gases and the ORC. From a thermodynamic point of view, this solution introduces an efficiency penalty since the hot oil temperature is lower than the ICE flue gases. In this work a temperature difference of $20^{\circ} \mathrm{C}$ is considered between flue gases and hot oil loop (i.e., the hot oil is $20^{\circ} \mathrm{C}$ lower than flue gases).

\subsection{Optimization algorithm}

To tackle the optimization problem described in Section 2, we devised an ad hoc algorithm able to optimize the cycle variables (i.e., pressures, temperatures, etc.), the mixture composition and the heat integration between the ORC streams and the available heat sources and sinks in a systematic and efficient way. The al-gorithm is an adaption of the one proposed by Gassner and Maré-chal [47] for the multi-objective optimization of biofuel production plants. It is based on the black-box strategy for process optimiza-tion [48]: the optimization algorithm considers only the indepen-dent decision variables (a few ones) and design specification constraints while all the dependent variables (e.g., stream proper-ties) and equipment models (e.g., energy and mass balance equa-tions) are hidden into the process/cycle simulation model (the black-box). The cycle simulation model is run for each solution sampled by the optimization algorithm like a black-box function. The main advantage of the black-box strategy compared to the equation oriented (where all the model equations and stream variables are included in the optimization problem [48]) is the limited number of optimization variables which considerably im-proves the probability of finding the global optimum [18]. On the other hand, the cycle simulation may fail to reach convergence for some (random) combinations of the input variables. Moreover, the output of the cycle simulation model may be non-smooth (nondifferentiable or discontinuous) and noisy.

The block-flow diagram of the proposed algorithm is shown in Fig. 2. At the upper level, the evolutionary algorithm PGS-COM [49] optimizes the independent cycle variables, namely the evaporating and condensing pressure, the turbine inlet temperature, and the mixture composition. At the lower level, for each combination of variables sampled by PGS-COM, the ORC is simulated in Matlab ${ }^{\circledR}$ $\mathrm{R} 2015 \mathrm{~b}$ [50] to determine the temperatures, pressures and enthalpies of all the streams.

REFPROP v9.1 is used to evaluate the thermodynamic properties. Once all the stream temperatures of the ORC are determined, the heat integration between ORC streams and heat sources/heat sinks is optimized with the methodology proposed by Maréchal and Kalitventzeff [51]. Given the available hot and cold streams

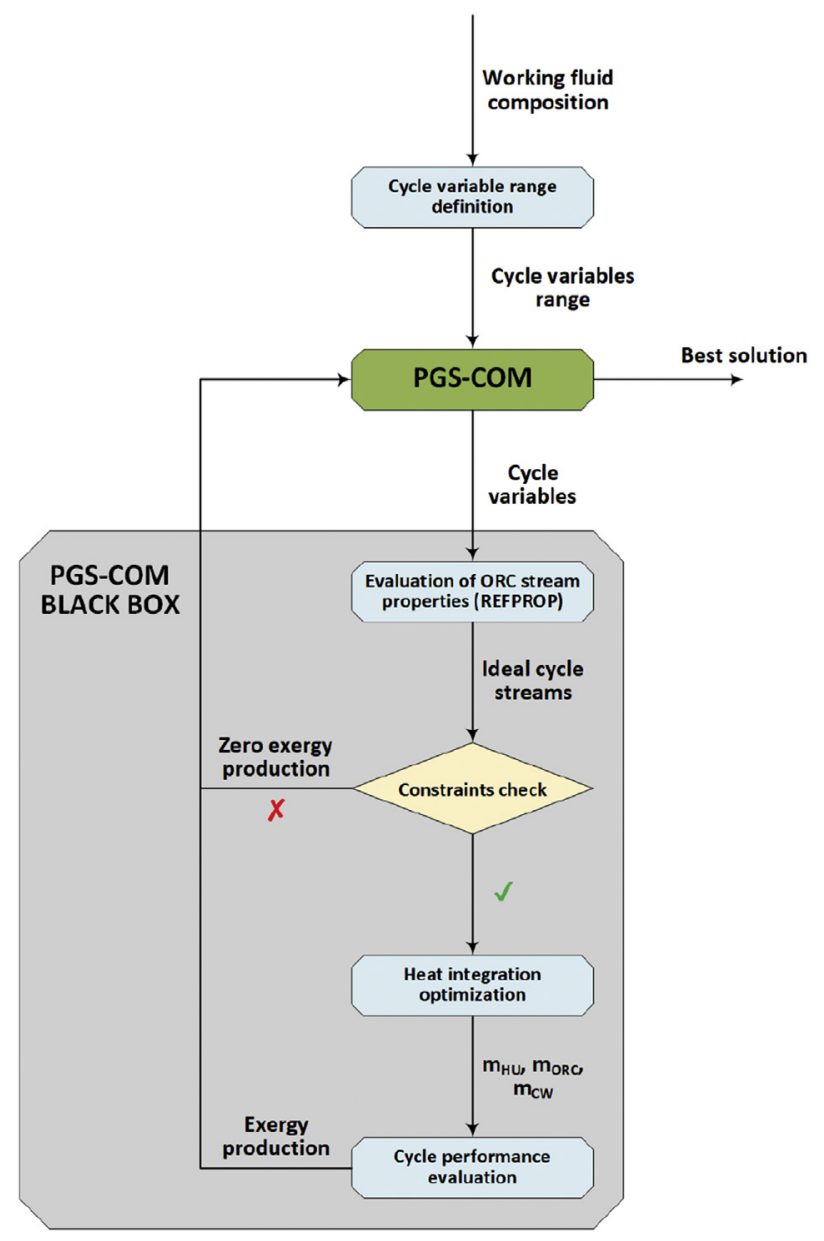

Fig. 2. Block diagram of the optimization algorithm.

(including the superheated vapor discharged from the ORC turbine which could be used within a regenerator), the heat integration methodology determines the maximum mass flow rate of the working fluid which can be generated (the so called "maximum heat recovery target"). After determining the ORC mass flow rate, the mechanical power recovered by the ORC and the exergy efficiency of the ORC system can be easily determined. The exergy efficiency value is returned to PGS-COM as output of the black-box function (which comprises the cycle model and the heat integration methodology). Then, PGS-COM proceeds with its search procedure and generates a new set of solutions, which need to be evaluated.

It is worth noting that the routines for the calculation of the fluid properties and the heat integration method may feature nondifferentiable outputs making the black-box function non-smooth. Indeed, we noticed that for a few pure fluids and several mixtures the flash algorithm for the evaluation of the thermody-namic properties has convergence problems, especially in the proximity of the critical point. As far as the heat integration methodology is concerned (see Section 3.2.2), the activation of pinch points within the heat cascade causes non-differentiable variations of the mass flow rate of ORC which can be generated [23]. For these reasons, gradient-based algorithms are not suitable to tackle such black-box problem and a robust derivative-free al-gorithm must be used.

\subsubsection{PGS-COM}

PGS-COM is a hybrid evolutionary algorithm specifically 
developed for the optimization of energy systems and chemical processes [23,52] with the black-box strategy. In general, PGS-COM can tackle non-smooth and discontinuous black-box problems with linear and nonlinear unrelaxable constraints (i.e., constraints which cannot be violated since they guarantee the physical feasibility of the system/cycle [18]) as well as hidden constraints (i.e., not explicitly known and appearing, for instance, when the cycle simulation crashes [53]). PGS-COM combines three direct-search derivative-free methods: Constrained Particle Swarm (PSO) [54], Generating Set Search (GSS) [55] and Complex [56]. During each iteration three steps are performed: first, an update of the particle swarm population, then an optional poll step of the GSS in the neighborhood of the best solution found so far, and finally a few optional iterations of the Complex method [57]. The particle swarm step explores the feasible region rapidly identifying promising regions while the GSS poll step intensifies the search in the most promising region. The Complex iterations, which are computationally expensive and can be not effective analyzing noisy problems, are executed only if the GSS poll step fails to find improving solutions. The combination of the GSS and Complex steps avoids premature convergence to suboptimal solutions and make the local search more robust with respect to discontinuities, nonsmoothness and noise of the objective function. The algorithm stops when either (i) the maximum distance between the best particle and the remaining particles, the step size parameter of the GSS step, the maximum distance between the best solution and the solutions used by the Complex search are below a given threshold values, or (ii) when the best solution found does not improve for a certain number of iterations or (iii) when the maximum specified number of function evaluations is exceeded.

Similarly to other meta-heuristic algorithms, there is no guarantee on the quality of the returned solutions and the convergence rate is considerably lower than gradient-based algorithms. Nevertheless, PGS-COM has been extensively tested [49] and successfully applied for the optimization of heat recovery steam cycles [58], ORCs [23,25], absorption-based $\mathrm{CO}_{2}$ capture processes [59,60], synthesis of heat exchangers networks [61], supercritical $\mathrm{CO}_{2}$ oxycombustion cycles [52], CHP systems [62] and biogas upgrading processes [63].

In this work, all constraints listed in Section 2 have been dealt with as unrelaxable constraints (either linear or non-linear, depending on the type) and the setup algorithm options recommended in Ref. [49] have been adopted. The maximum number of function evaluations has been limited to 2000 and, for each working fluid, the cycle optimization has been repeated 5 times so as to account for the stochasticity of the search procedure and minimize the risk of converging into a local minima.

\subsubsection{Heat integration algorithm}

For each solution sampled by PGS-COM, first, the thermodynamic properties (i.e., pressure, temperature, density, enthalpy and entropy) of the ideal cycle streams are calculated. A Matlab ${ }^{\circledR}$ $\mathrm{R} 2015 \mathrm{~b}$ routine checks if all the constraints specified in Section 2 are met. If one or more of them are violated, the calculation of the cycle performance is stopped and the exergy efficiency is set to zero, according to the "extreme barrier" approach adopted by PGSCOM to handle the nonlinear constraints [49]. The net specific work (per unit of mass of working fluid) of the ideal cycle is computed with the streams enthalpies:

$$
\begin{aligned}
& \mathrm{w}_{\mathrm{EXP}}=\left(\mathrm{h}_{\text {IN,EXP }}-\mathrm{h}_{\mathrm{OUT}, \mathrm{EXP}}\right) \\
& w_{\mathrm{PUM}}=\left(\mathrm{h}_{\mathrm{OUT}, \mathrm{PUM}}-\mathrm{h}_{\mathrm{IN}, \mathrm{PUM}}\right)
\end{aligned}
$$

$$
\mathrm{w}_{\mathrm{NET}, \mathrm{CYCLE}}=\mathrm{w}_{\mathrm{EXP}}-\mathrm{w}_{\mathrm{PUM}}
$$

The specific (per unit of mass of cooling water) power consumption required by the circulation pump of the cooling water is assessed assuming uncompressible flow (i.e., constant water density $\left.\rho_{C W}\right)$, ideal pump, and a circuit pressure drop $\Delta p_{C W}$ of 0.5 bar:

$\mathrm{w}_{\mathrm{CW}}=\frac{1}{\rho_{\mathrm{CW}}} \Delta \mathrm{p}_{\mathrm{CW}}$

For the CHP scenarios, the specific exergy value (per unit of mass of hot water) of the hot water provided to the heat user $e x_{H U}$ can be computed as a function of the specific heat $\left(h_{I N, H U}-h_{O U T, H U}\right)$ and conversion efficiency of the ideal Lorentz cycle $\eta_{H U}$ :

$\mathrm{ex}_{\mathrm{HU}}=\left(\mathrm{h}_{\mathrm{IN}, \mathrm{HU}}-\mathrm{h}_{\mathrm{OUT}, \mathrm{HU}}\right) \eta_{\mathrm{HU}}$

Once all the specific and intensive properties are known, only the mass flow rates of ORC working fluid, cooling water and hot water loop (only for the CHP scenarios) need to be determined. To this end, we adopted the energy targeting methodology proposed by Maréchal et al. [51] which solves the following problem:

- given the temperatures and thermal power of the available hot and cold streams (i.e., hot engine streams),

- given the inlet/outlet temperatures and enthalpies of the ORC streams, cooling water and hot water loop,

- given the net specific work of the ORC $w_{N E T, C Y C L E}$, the net specific power consumption of the cooling water flow $w_{C W}$ and (only for CHP cases) the specific exergy value of the hot water $e x_{H U}$,

- given the minimum allowed temperature differences of the heat transfer processes between hot and cold streams $\Delta T_{H T}$ (optionally different for each stream [64]).

The methodology determines the mass flow rates of ORC working fluid $\dot{m}_{O R C}$, cooling water $\dot{m}_{C W}$ and hot water for the heat user $\dot{m}_{H U}$ which maximizes the exergy generated by the ORC system (i.e., the numerator of Eq. (1) for MEC scenarios and that of Eq.

(5) for CHP scenarios).

The heat integration is based on a reformulation of the "heat cascade" [65] as a linear program [66] considering the mass flow rates of the unknown streams (ORC, cooling water and hot water) as optimization variables. As in pinch analysis and other energy targeting methodologies, the basic assumption is that hot and cold streams can exchange heat with the only restriction of the minimum allowed heat transfer temperature difference $\Delta T_{H T}$.

First, temperatures of hot and cold streams are shifted down and up, respectively, of the assumed $\Delta T_{H T}$. The shifted stream temper-atures are ordered and the whole range is divided into a certain of intervals $n_{T}$. In the classic method for streams with constant heat capacity [66], temperature intervals are defined only by the inlet stream temperatures so as to minimize the size of the optimization problem. However, here also supercritical fluids and zeotropic mixtures are considered and for these streams it is not correct to assume constant heat capacity over large temperature intervals. For this reason, the whole temperature range is divided into 100 temperature intervals, each one with a width lower than 2 ${ }^{\circ} \mathrm{C}$. In our implementation, the following linear program is formulated:

$\max \dot{\mathrm{m}}_{\mathrm{ORC}} \mathrm{w}_{\mathrm{NET}, \mathrm{CYCLE}}+\dot{\mathrm{m}}_{\mathrm{HU}} \mathrm{ex}_{\mathrm{HU}}-\dot{\mathrm{m}}_{\mathrm{CW}} \mathrm{w}_{\mathrm{P}, \mathrm{CW}}$

subject to: 


$$
\begin{aligned}
& \sum_{\mathrm{k}_{\mathrm{H}, \mathrm{i}}} \dot{\mathrm{Q}}_{\mathrm{k}_{\mathrm{H}, \mathrm{i}}}-\sum_{\mathrm{k}_{\mathrm{C}, \mathrm{i}}} \dot{\mathrm{Q}}_{\mathrm{k}_{\mathrm{C}, \mathrm{i}}}+\mathrm{R}_{\mathrm{i}-1}-\mathrm{R}_{\mathrm{i}}-\dot{\mathrm{m}}_{\mathrm{ORC}} \mathrm{q}_{\mathrm{IN}, \mathrm{i}}-\dot{\mathrm{m}}_{\mathrm{ORC}} \mathrm{q}_{\mathrm{OUT}, \mathrm{i}} \\
& -\dot{\mathrm{m}}_{\mathrm{CW}} \mathrm{q}_{\mathrm{CW}, \mathrm{i}}-\dot{\mathrm{m}}_{\mathrm{HU}} \mathrm{q}_{\mathrm{HU}, \mathrm{i}} \\
& =0 \quad \forall \mathrm{i} \in\left[1, \mathrm{n}_{\mathrm{T}}\right]
\end{aligned}
$$

$\dot{\mathrm{m}}_{\mathrm{ORC}}, \dot{\mathrm{m}}_{\mathrm{CW}}, \dot{\mathrm{m}}_{\mathrm{HU}} \geq 0$

$\mathrm{R}_{\mathrm{i}} \geq 0 \quad \forall \mathrm{i} \in\left[1, \mathrm{n}_{\mathrm{T}}\right]$

$\mathrm{R}_{0}=0$ and $\mathrm{R}_{\mathrm{n}_{\mathrm{T}}}=0$

In Eq. (16), $\dot{Q}_{k_{H, i}}$ and $\dot{Q}_{k_{C, i}}$ denote the thermal power provided and absorbed by the $k_{H}$ hot stream and the $k_{C}$ cold stream in the $i$-th temperature interval of the heat cascade. $R_{i}$ is the excess heat (not absorbed by the cold streams in the $i$-th temperature intervals) which cascades to the lower temperature interval while $R_{i-1}$ is the excess heat received from the higher temperature interval. As far as the streams with unknown mass flow rate are concerned, $\dot{m}_{j}$ denotes the mass flow rate of the ORC working fluid, cooling water and, only for CHP cases, hot water; $q_{I N, i}$ and $q_{O U T, i}$ are respectively the specific heat absorbed and released by the ORC in the $i$-th temperature interval of the heat cascade, while $q_{C W, i}$ and $q_{H U, i}$ are the specific heat absorbed respectively by cooling water and hot water in the $i$-th temperature interval. Eq. (18) guarantees that heat can only flow from higher to lower temperature intervals and Eq.
(19) imposes the boundary conditions for the heat cascade $\left(R_{0}\right.$ and $R_{n_{T}}$ must be zero since there is no temperature interval above the first one and below the last one).

The above-described linear program has been in Matlab ${ }^{\circledR}$ R2015b and then solved with the default "linprog" algorithm [67]. Thanks to the efficiency of today's linear programming algorithms and calculators, the computational time is limited to a few seconds ( $<5-6 \mathrm{~s}$ in the woest case). This is an important factor since the linear program needs to be solved for each solution sampled by PGS-COM, i.e., 2000 times for each fluid.

From a practical point of view, in the MEC cases, the linear program tends to maximize the mass flow rate of ORC which can be generated from the available heat sources and to minimize the cooling water flow rate. In the CHP cases, both the ORC flow rate and the hot water for the heat user have positive objective function contributions and, as a result, they are competing each other.

Since both PGS-COM and the energy targeting methodology maximize the exergy efficiency of the ORC systems, the optimized solutions returned by the overall optimization algorithm feature the minimum total exergy loss (sum of the exergy wasted in the heat transfer processes and the exergy given to the cooling water).

\subsubsection{Cycle performance indexes}

Once the mass flow rates of ORC, hot water and cooling water have been determined, the exergy efficiency of the ORC system can be easily determined with Eqs. (20) and (21) and returned to PGSCOM as objective function values.

\begin{tabular}{|c|c|c|c|c|c|}
\hline & Compound\#1 & Compound\#2 & Chemical formula\#1 & Chemical formula\#2 & Mixing parameters \\
\hline $\begin{array}{l}\text { Lower temperature flue } \\
\text { gases Man S60-MC6 }\end{array}$ & $\begin{array}{l}\text { Ammonia } \\
\text { HCFO-1233zde } \\
\text { HFO-1336mzz } \\
\text { Dimethyl ether } \\
\text { Dimethyl ethe } \\
\text { Dimethyl ether } \\
\text { Dimethyl ether } \\
\text { Dimethyl ether } \\
\text { Dimethyl ether } \\
\text { Butane } \\
\text { Butane } \\
\text { Butane } \\
\text { Butane } \\
\text { Isobutane } \\
\text { Isobutane } \\
\text { Isobutane } \\
\text { Isobutane } \\
\text { Cyclohexane } \\
\text { Cyclohexane }\end{array}$ & $\begin{array}{l}\text { Water } \\
\text { HFC-134a } \\
\text { HFC-134a } \\
\text { Isopentane } \\
\text { Pentane } \\
\text { Ethanol } \\
\text { Toluene } \\
\text { Methanol } \\
\text { Dimethyl carbonate } \\
\text { Isopentane } \\
\text { pentane } \\
\text { Cyclohexane } \\
\text { Hexane } \\
\text { Isopentane } \\
\text { Pentane } \\
\text { Cyclohexane } \\
\text { Hexane } \\
\text { Butene } \\
\text { Isobutene }\end{array}$ & $\begin{array}{l}\mathrm{NH}_{3} \\
\mathrm{C}_{3} \mathrm{H}_{2} \mathrm{ClF}_{3} \\
\mathrm{C}_{4} \mathrm{H}_{2} \mathrm{~F}_{6} \\
\mathrm{C}_{2} \mathrm{H}_{6} \mathrm{O} \\
\mathrm{C}_{2} \mathrm{H}_{6} \mathrm{O} \\
\mathrm{C}_{2} \mathrm{H}_{6} \mathrm{O} \\
\mathrm{C}_{2} \mathrm{H}_{6} \mathrm{O} \\
\mathrm{C}_{2} \mathrm{H}_{6} \mathrm{O} \\
\mathrm{C}_{2} \mathrm{H}_{6} \mathrm{O} \\
\mathrm{C}_{4} \mathrm{H}_{10} \\
\mathrm{C}_{4} \mathrm{H}_{10} \\
\mathrm{C}_{4} \mathrm{H}_{10} \\
\mathrm{C}_{4} \mathrm{H}_{10} \\
\mathrm{C}_{4} \mathrm{H}_{10} \\
\mathrm{C}_{4} \mathrm{H}_{10} \\
\mathrm{C}_{4} \mathrm{H}_{10} \\
\mathrm{C}_{4} \mathrm{H}_{10} \\
\mathrm{C}_{6} \mathrm{H}_{12} \\
\mathrm{C}_{6} \mathrm{H}_{12}\end{array}$ & $\begin{array}{l}\mathrm{H}_{2} \mathrm{O} \\
\mathrm{C}_{2} \mathrm{H}_{2} \mathrm{~F}_{4} \\
\mathrm{C}_{2} \mathrm{H}_{2} \mathrm{~F}_{4} \\
\mathrm{C}_{5} \mathrm{H}_{12} \\
\mathrm{C}_{5} \mathrm{H}_{12} \\
\mathrm{C}_{2} \mathrm{H}_{6} \mathrm{O} \\
\mathrm{C}_{7} \mathrm{H}_{8} \\
\mathrm{C}_{2} \mathrm{H}_{4} \mathrm{O} \\
\mathrm{C}_{3} \mathrm{H}_{6} \mathrm{O}_{3} \\
\mathrm{C}_{5} \mathrm{H}_{12} \\
\mathrm{C}_{5} \mathrm{H}_{12} \\
\mathrm{C}_{6} \mathrm{H}_{12} \\
\mathrm{C}_{6} \mathrm{H}_{14} \\
\mathrm{C}_{5} \mathrm{H}_{12} \\
\mathrm{C}_{5} \mathrm{H}_{12} \\
\mathrm{C}_{6} \mathrm{H}_{12} \\
\mathrm{C}_{6} \mathrm{H}_{14} \\
\mathrm{C}_{4} \mathrm{H}_{8} \\
\mathrm{C}_{4} \mathrm{H}_{8}\end{array}$ & $\begin{array}{l}\text { Estimated } \\
\text { Estimated } \\
\text { Estimated } \\
\text { Calibrated } \\
\text { Calibrated } \\
\text { Calibrated } \\
\text { Calibrated } \\
\text { Calibrated } \\
\text { Calibrated } \\
\text { Calibrated } \\
\text { Calibrated } \\
\text { Calibrated } \\
\text { Calibrated } \\
\text { Calibrated } \\
\text { Calibrated } \\
\text { Calibrated } \\
\text { Calibrated } \\
\text { Calibrated } \\
\text { Calibrated }\end{array}$ \\
\hline $\begin{array}{l}\text { Higher temperature flue } \\
\text { gases Wärtsilä 46DF }\end{array}$ & $\begin{array}{l}\text { Ammonia } \\
\text { HCFO-1233zde } \\
\text { HFO-1336mzz } \\
\text { Cyclopentane } \\
\text { Cyclopentane } \\
\text { Cyclopentane } \\
\text { MM } \\
\text { MM } \\
\text { Water } \\
\text { Isopentane } \\
\text { Isopentane } \\
\text { Isopentane } \\
\text { Pentane } \\
\text { Pentane } \\
\text { Pentane } \\
\text { Pentane } \\
\text { Pentane } \\
\text { Cyclohexane } \\
\text { Hexane }\end{array}$ & $\begin{array}{l}\text { Water } \\
\text { HFC-134a } \\
\text { HFC-134a } \\
\text { cis-Butene } \\
\text { Heptane } \\
\text { Isooctane } \\
\text { D4 } \\
\text { MDM } \\
\text { Methanol } \\
\text { Cyclohexane } \\
\text { Hexane } \\
\text { Methylcyclohexane } \\
\text { Cyclohexane } \\
\text { Hexane } \\
\text { Methylcyclohexane } \\
\text { Heptane } \\
\text { Toluene } \\
\text { Toluene } \\
\text { Octane }\end{array}$ & $\begin{array}{l}\mathrm{NH}_{3} \\
\mathrm{C}_{3} \mathrm{H}_{2} \mathrm{ClF}_{3} \\
\mathrm{C}_{4} \mathrm{H}_{2} \mathrm{~F}_{6} \\
\mathrm{C}_{5} \mathrm{H}_{10} \\
\mathrm{C}_{5} \mathrm{H}_{10} \\
\mathrm{C}_{5} \mathrm{H}_{10} \\
\mathrm{C}_{6} \mathrm{H}_{18} \mathrm{OSi}_{2} \\
\mathrm{C}_{6} \mathrm{H}_{18} \mathrm{OSi}_{3} \\
\mathrm{H}_{2} \mathrm{O} \\
\mathrm{C}_{5} \mathrm{H}_{12} \\
\mathrm{C}_{5} \mathrm{H}_{12} \\
\mathrm{C}_{5} \mathrm{H}_{12} \\
\mathrm{C}_{5} \mathrm{H}_{12} \\
\mathrm{C}_{5} \mathrm{H}_{12} \\
\mathrm{C}_{5} \mathrm{H}_{12} \\
\mathrm{C}_{5} \mathrm{H}_{12} \\
\mathrm{C}_{5} \mathrm{H}_{12} \\
\mathrm{C}_{6} \mathrm{H}_{12} \\
\mathrm{C}_{6} \mathrm{H}_{14}\end{array}$ & $\begin{array}{l}\mathrm{H}_{2} \mathrm{O} \\
\mathrm{C}_{2} \mathrm{H}_{2} \mathrm{~F}_{4} \\
\mathrm{C}_{2} \mathrm{H}_{2} \mathrm{~F}_{4} \\
\mathrm{C}_{4} \mathrm{H}_{8} \\
\mathrm{C}_{7} \mathrm{H}_{6} \\
\mathrm{C}_{8} \mathrm{H}_{18} \\
\mathrm{C}_{8} \mathrm{H}_{24} \mathrm{O}_{4} \mathrm{Si}_{4} \\
\mathrm{C}_{8} \mathrm{H}_{24} \mathrm{O}_{2} \mathrm{Si}_{3} \\
\mathrm{CH}_{4} \mathrm{O} \\
\mathrm{C}_{6} \mathrm{H}_{12} \\
\mathrm{C}_{6} \mathrm{H}_{14} \\
\mathrm{C}_{7} \mathrm{H}_{14} \\
\mathrm{C}_{6} \mathrm{H}_{12} \\
\mathrm{C}_{6} \mathrm{H}_{14} \\
\mathrm{C}_{7} \mathrm{H}_{14} \\
\mathrm{C}_{7} \mathrm{H}_{16} \\
\mathrm{C}_{7} \mathrm{H}_{8} \\
\mathrm{C}_{7} \mathrm{H}_{8} \\
\mathrm{C}_{8} \mathrm{H}_{18}\end{array}$ & $\begin{array}{l}\text { Estimated } \\
\text { Estimated } \\
\text { Estimated } \\
\text { Estimated } \\
\text { Estimated } \\
\text { Estimated } \\
\text { Estimated } \\
\text { Estimated } \\
\text { Calibrated } \\
\text { Calibrated } \\
\text { Calibrated } \\
\text { Calibrated } \\
\text { Calibrated } \\
\text { Calibrated } \\
\text { Calibrated } \\
\text { Calibrated } \\
\text { Calibrated } \\
\text { Calibrated } \\
\text { Calibrated }\end{array}$ \\
\hline
\end{tabular}

Table 5

Binary mixtures selected for the both engines. 
$\eta_{\mathrm{EX}}=\frac{\dot{\mathrm{m}}_{\mathrm{ORC}} \mathrm{W}_{\mathrm{NET}, \mathrm{CYCLE}}-\dot{\mathrm{m}}_{\mathrm{CW}} \mathrm{W}_{\mathrm{CW}}}{\dot{\mathrm{Q}}_{\mathrm{F}}\left(1-\frac{\mathrm{T}_{0}}{\mathrm{~T}_{\mathrm{ML}, \mathrm{F}}}\right)+\dot{\mathrm{Q}}_{\mathrm{A}}\left(1-\frac{\mathrm{T}_{0}}{\mathrm{~T}_{\mathrm{ML}, \mathrm{A}}}\right)+\dot{\mathrm{Q}}_{\mathrm{JW}}\left(1-\frac{\mathrm{T}_{0}}{\mathrm{~T}_{\mathrm{ML} . \mathrm{JW}}}\right)}$

$\eta_{\mathrm{EX}}=\frac{\dot{\mathrm{m}}_{\mathrm{ORC}} \mathrm{w}_{\mathrm{NET}, \mathrm{CYCLE}}-\dot{\mathrm{m}}_{\mathrm{HU}} \mathrm{eh}_{\mathrm{HU}}-\dot{\mathrm{m}}_{\mathrm{CW}} \mathrm{w}_{\mathrm{CW}}}{\dot{\mathrm{Q}}_{\mathrm{F}}\left(1-\frac{\mathrm{T}_{0}}{\mathrm{~T}_{\mathrm{ML}, \mathrm{F}}}\right)+\dot{\mathrm{Q}}_{\mathrm{A}}\left(1-\frac{\mathrm{T}_{0}}{\mathrm{~T}_{\mathrm{ML}, \mathrm{A}}}\right)+\dot{\mathrm{Q}}_{\mathrm{JW}}\left(1-\frac{\mathrm{T}_{0}}{\mathrm{~T}_{\mathrm{ML}, \mathrm{JW}}}\right)}$

In addition to the exergy efficiency, we coded a routine to estimate the minimum number of stages required by the turbine. This is an important fluid selection parameter since, for the relatively small size of ORC plants, it is important to limit the complexity and the cost of the turbine [23]. Given the volumetric flow rates of working fluid at turbine inlet and outlet, we assumed to adopt an axial turbine and considered as limiting criteria the maximum enthalpy drop and the maximum volumetric expansion ratio, as previously done by Martelli et al. [23]. At beginning, the procedure computes the maximum enthalpy drop (work) achievable by an ideal impulse stage with axial outlet velocity designed for the maximum pitch-line of $255 \mathrm{~m} / \mathrm{s}$, corresponding to $130 \mathrm{~kJ} / \mathrm{kg}$. Another factor limiting the stage load is the volumetric expansion ratio, defined as the ratio between the outlet and the inlet volume flow rates, which should be limited to 15 [68] in order to have sufficiently low fluid dynamic losses.

\section{Results}

For each case reported in Table 2 and for each fluid listed in Table 3, Table 4, and Table 5 we applied the optimization algorithm described in Section 2 to optimize the ORC. In total, we optimized 202 cycles. Since an optimization run took about $30 \mathrm{~min}$ and was repeated 5 times to minimize the risk of finding suboptimal solutions, the total required computational was approximately 21 days. The whole set of results is reported in the supplementary online material. In the following subsections, we report only the results for the best three pure fluids and best three mixtures of each case (see

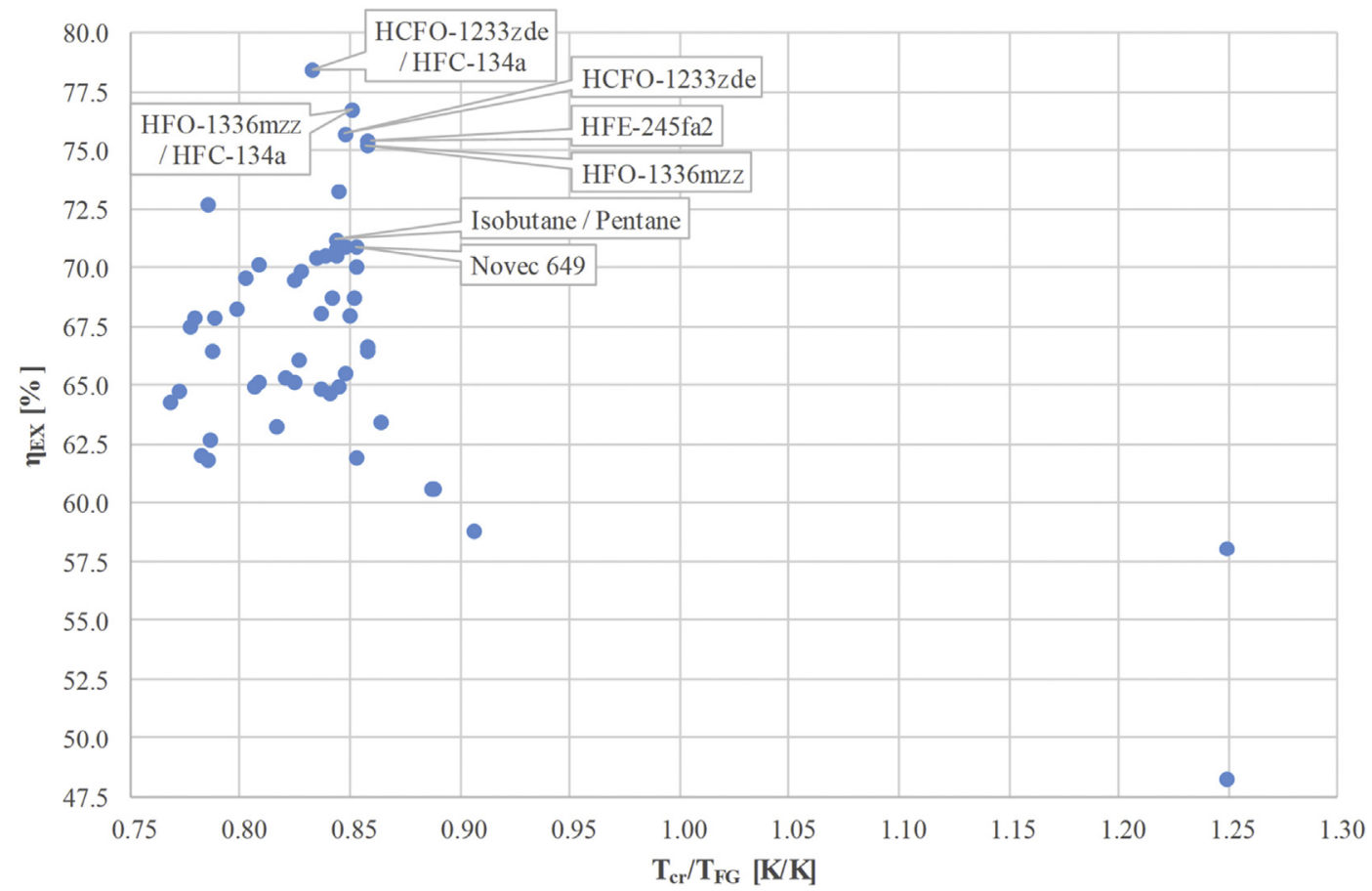

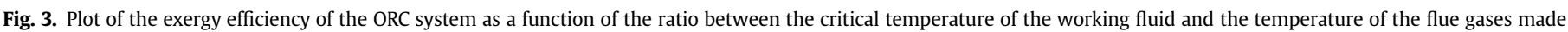
available by the engine for the LT-MEC case.

Table 6

Best pure fluids for LT-MEC scenario.

\begin{tabular}{|c|c|c|c|c|}
\hline & \multirow{2}{*}{$\begin{array}{l}\text { Unit of } \\
\text { measurement }\end{array}$} & \multicolumn{3}{|c|}{ LT-MEC - Pure fluids } \\
\hline & & HCFO-1233zde & HFE-245fa2 & HFO-1336mzz \\
\hline Heat transfer from ICE flue gases & - & Direct & Direct & Direct \\
\hline Working fluid mass flow rate & $\mathrm{kg} / \mathrm{s}$ & 28.13 & 27.74 & 30.48 \\
\hline Boiler pressure & bar & 38.61 & 36.17 & 30.52 \\
\hline Condensing pressure & bar & 1.75 & 1.19 & 1.02 \\
\hline Expander inlet temperature & ${ }^{\circ} \mathrm{C}$ & 196.31 & 197.86 & 195.38 \\
\hline Expander pressure ratio & - & 22.07 & 30.43 & 29.91 \\
\hline$\Delta \mathrm{h}$ expander & $\mathrm{kJ} / \mathrm{kg}$ & 67.18 & 67.45 & 61.06 \\
\hline Expander volumetric ratio & - & 25.88 & 39.43 & 38.99 \\
\hline Estimated expander number of stages & - & 2 & 2 & 2 \\
\hline Net ORC power & $\mathrm{kW}$ & 1802.5 & 1795.9 & 1790.1 \\
\hline$\eta_{\mathrm{MEC}, \mathrm{ORC}}$ & $\%$ & 19.88 & 19.81 & 19.74 \\
\hline$\eta_{\mathrm{EX}, \mathrm{ORC}}$ & $\%$ & 75.71 & 75.44 & 75.19 \\
\hline$\eta_{\mathrm{MEC}, \mathrm{ICE}+\mathrm{ORC}}$ & $\%$ & 58.36 & 58.33 & 58.30 \\
\hline
\end{tabular}


A)
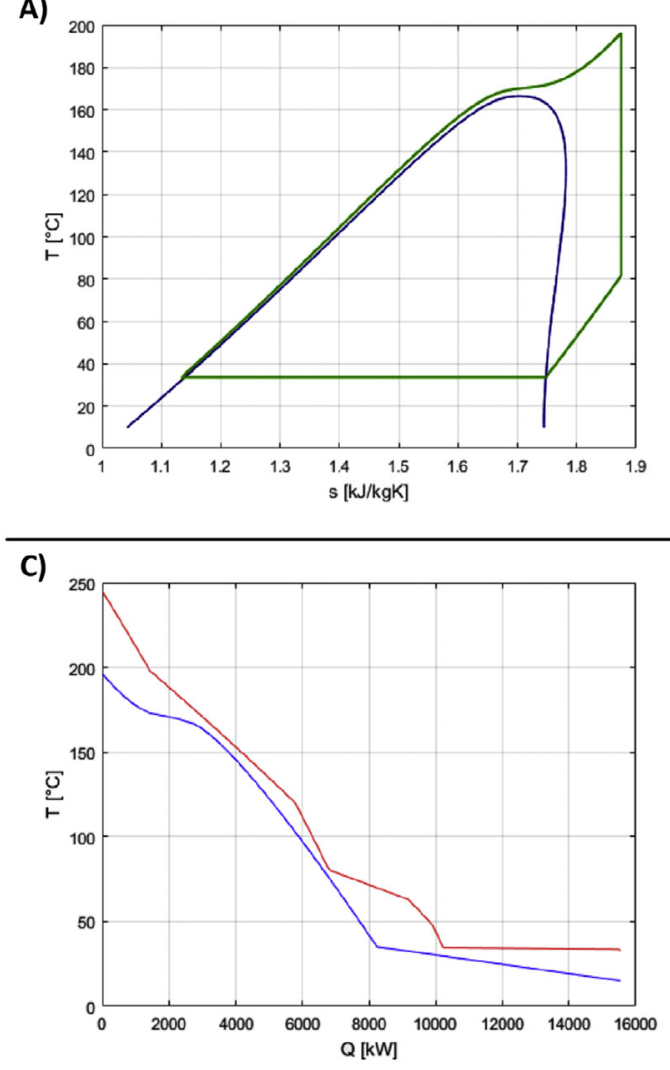

E)

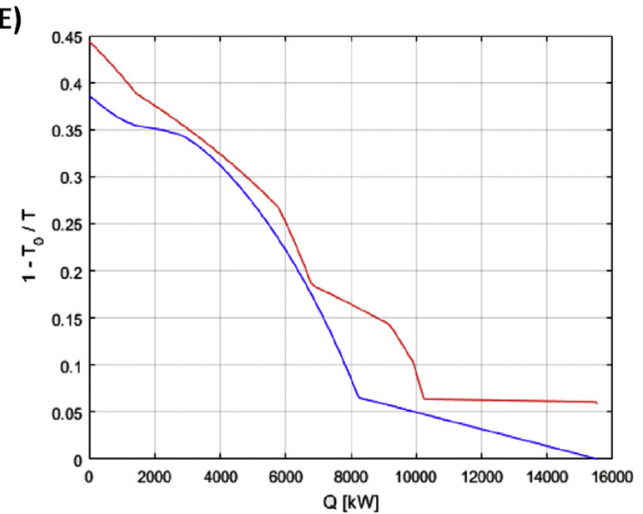

B)

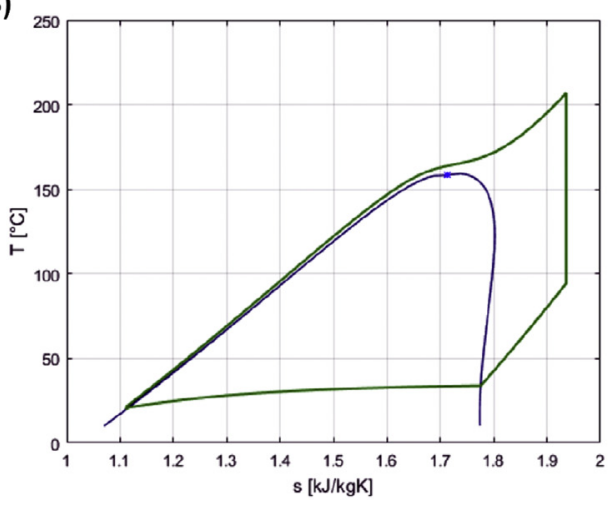

D)

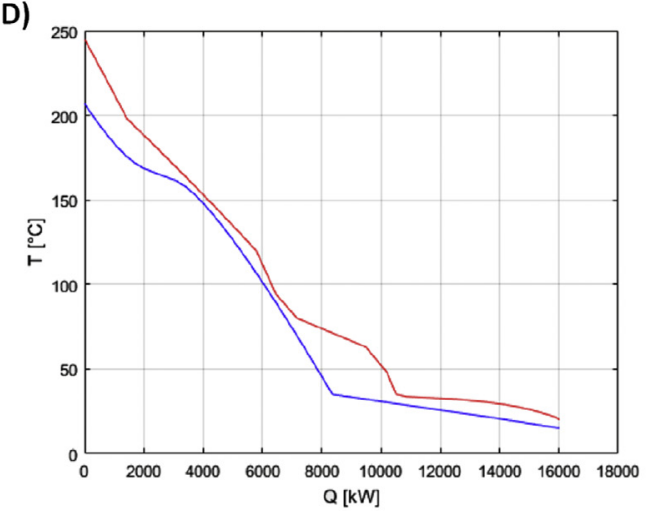

F)

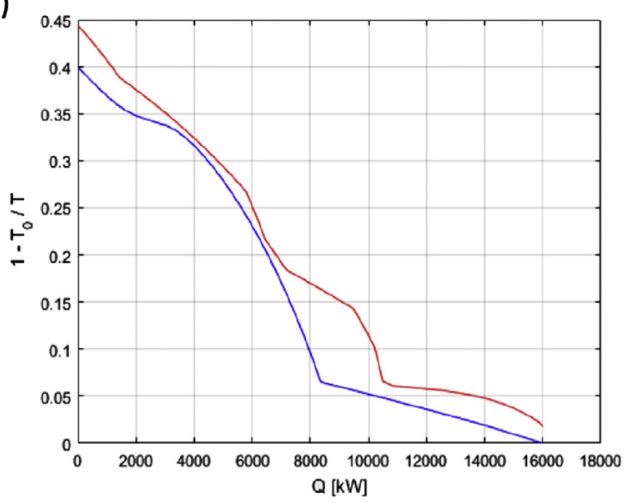

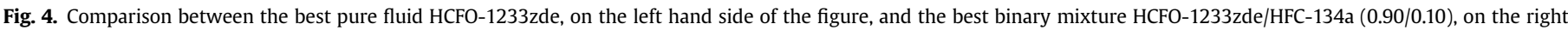

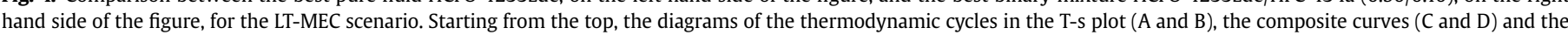
Carnot curves ( $\mathrm{E}$ and $\mathrm{F}$ ) of the heat transfer processes.

Tables 6-13) and discuss the main findings.

\subsection{Results for the LT-MEC scenario}

The exergy efficiency of the optimized ORC systems (as defined in Eq. (5)) is plotted in Fig. 3 as a function of the ratio between the critical temperature of the fluid $\mathrm{T}_{\mathrm{CR}}$ and the exhaust temperature of the engine $\mathrm{T}_{\mathrm{FG}}$ (where both temperatures are measured in Kelvin). The critical temperature of the binary mixtures have been assessed using REFPROP. Results indicate that the best three pure fluids are HCFO-1233zde, HFE-245fa2, and HFO-1336mzz while the best mixtures are HCFO-1233zde/HFC-134a (0.9/0.1), HFO-1336mzz/ HFC-134a (0.97/0.03), and isobutane/pentane (0.56/0.44). Also the novel fluid Novec 649 achieves high performances. An interesting result is that the working fluids achieving the highest efficiency feature a $\mathrm{T}_{\mathrm{CR}} / \mathrm{T}_{\mathrm{FG}}$ ratio in the range $0.77-0.86$.

The three pure fluids with highest efficiency (HCFO-1233zde, HFE-245fa2, and HFO-1336mzz) are also non-flammable, and thus they can be directly coupled with the flue gases without the need of an intermediate hot oil loop. For all the three fluids, the optimal cycle is supercritical with a regenerator at turbine outlet to recover the heat made available by the superheated vapor at turbine outlet. The optimal cycle variables are reported in Table 6 . The difference in ORC power output between the three fluids is limited to $12 \mathrm{~kW}$, corresponding to a negligible difference $(0.14$ percentage points) in the net electric efficiency of the overall system (ICE + ORC). Also the mass flow rates, pressures and temperatures of the optimized ORCs are similar. The optimal condensing pressure, being above the 
atmospheric value, is particularly favorable because of the reduced air leakage issues. For the three fluids, two axial stages are necessary due to the high volumetric expansion ratio (in the range 26-39). From an environmental point of view, HCFO-1233zde and HFO-1336mzz are preferable because of their lower GWP (respectively equal to 1 and 2) compared to HFE-245fa2 (GWP equal to 812).

Fig. 4 (A), (C), and (E), shows the composite curves, Carnot curves and T-entropy diagram for the cycle with HCFO-1233zde. The Carnot curves [69] provide the direct representation of the exergy loss in the heat transfer process. In these curves (see Fig. $4(\mathrm{E})$ and $(\mathrm{F})$ ), the $\mathrm{Y}$ axis reports the efficiency of a Carnot cycle working between the stream temperature $T$ and the dead state temperature $T_{0}$, i.e., $\left(1-T_{0} / T\right)$. As a result, the area between the hot and the cold curves is directly proportional to the exergy wasted in the heat transfer process. As shown in Fig. 4 (A), it is an isentropicexpansion fluid because the saturation curve of the vapor phase in the T-s diagram is almost vertical. Fig. 4 (C) shows that the pinch point between the two curves is at about $80^{\circ} \mathrm{C}$. This indicates that heat available above such temperature is the main factor limiting the mass flow rate of working fluid that can be generated. At lower temperatures, the heat made available by the jacket water and vapor de-superheating in the regenerator is more than required by the ORC.

The full result tables reported in the supplementary online indicate that close-to-maximum cycle performance are achieved also by HFE-347mcc, HFE-245cb2 and Novec 649. Among these fluids, Novec 649 appears to be a promising option since the ORC power production (1688 $\mathrm{kW})$ is close to the optimal value and the fluid properties are favorable (non-flammable, thermally stable up to $300{ }^{\circ} \mathrm{C}[40]$, and with low GWP $(=1)$ ). The optimal cycle is supercritical with an evaporating pressure lower than 20 bar, and the condensing pressure around 0.5 bar.

The best three binary mixtures for the Man S60-MC6 engine are HCFO-1233zde/HFC-134a (0.9/0.1), HFO-1336mzz/HFC-134a (0.97/ 0.03 ), and isobutane/pentane (0.56/0.44). Fig. 4 (B), (D), and (F), respectively show the composite curve, the Carnot curves the T-s diagram of the best mixture. The cycle configuration is supercritical in all the cases. As reported in Table 7, the cycle power output of $1868 \mathrm{~kW}$ for the best fluid and it drops to $1699 \mathrm{~kW}$ for the last mixture because it is flammable and requires the thermal oil loop. Differently from the pure fluids, the optimal turbine inlet temperatures vary considerably from one mixture to another. The turbine inlet pressure is lower than 43 bar for all the mixtures, so we do not envisage any technological problem related to thick components. In

Table 7

Best mixtures for LT-MEC scenario.

\begin{tabular}{|c|c|c|c|c|}
\hline \multirow[b]{2}{*}{ Compound 1} & \multirow{3}{*}{$\begin{array}{l}\text { Unit of } \\
\text { measurement }\end{array}$} & \multicolumn{3}{|c|}{ LT-MEC - Binary mixtures } \\
\hline & & \multirow{2}{*}{$\frac{\text { HCFO-1233zde }}{\text { HFC-134a }}$} & \multirow{2}{*}{$\frac{\text { HFO-1336mzz }}{\text { HFC-134a }}$} & \multirow{2}{*}{$\frac{\text { Isobutane }}{\text { Pentane }}$} \\
\hline Compound 2 & & & & \\
\hline Heat transfer from ICE flue gases & - & Direct & Direct & Therm. oil loop \\
\hline Mass fraction compound\#1 & - & 0.90 & 0.97 & 0.56 \\
\hline Mass fraction compound\#2 & - & 0.10 & 0.03 & 0.44 \\
\hline Working fluid mass flow rate & $\mathrm{kg} / \mathrm{s}$ & 27.20 & 30.47 & 16.13 \\
\hline Boiler pressure & bar & 42.17 & 31.55 & 38.60 \\
\hline Condensing pressure & bar & 1.99 & 1.05 & 2.14 \\
\hline Expander inlet temperature & ${ }^{\circ} \mathrm{C}$ & 206.85 & 195.07 & 170.02 \\
\hline Expander pressure ratio & - & 21.23 & 30.13 & 18.06 \\
\hline$\Delta \mathrm{h}$ expander & $\mathrm{kJ} / \mathrm{kg}$ & 71.98 & 62.32 & 111.53 \\
\hline Expander volumetric ratio & - & 23.14 & 38.52 & 28.63 \\
\hline Estimated expander number of stages & - & 2 & 2 & 2 \\
\hline Net ORC power & $\mathrm{kW}$ & 1867.8 & 1827.5 & 1694.7 \\
\hline$\eta_{\mathrm{MEC}, \mathrm{ORC}}$ & $\%$ & 20.60 & 20.16 & 18.69 \\
\hline$\eta_{\mathrm{EX}, \mathrm{ORC}}$ & $\%$ & 78.45 & 76.76 & 71.18 \\
\hline$\eta_{\mathrm{MEC}, \mathrm{ICE}+\mathrm{ORC}}$ & $\%$ & 58.68 & 58.48 & 57.83 \\
\hline
\end{tabular}

these cases, the volumetric ratio imposes the need of at least two expansion stages for all mixtures. The mass flow rate of the nonflammable mixtures (i.e., 27 and 30 respectively for the first and second best mixture) is almost double compared to the mixture of hydrocarbons $(16 \mathrm{~kg} / \mathrm{s})$. From the environmental point of view, HFC-134a does not seem a good option because of its high GWP (1430), even if the mass fraction in the optimized mixtures is low.

According to the results, the use of mixtures as working fluid leads to a gain of 0.72 percentage points in net mechanical efficiency of the ORC system, and 0.32 in the mechanical efficiency of the overall integrated system (ICE + ORC). On the other hand, it is important to notice that the calculation of the thermodynamic properties for the mixtures of HCFO-1233zde/HFC-134a and HFO-1336mzz/HFC-134a may be affected by inaccuracy of the equation of states because the mixing parameters used by REFPROP have been estimated with the method [46] (and not calibrated with experimental data).

Although the optimized fluid superheating temperatures are rather low $\left(195-205^{\circ} \mathrm{C}\right)$, since no data were found in the literature for the three best pure fluids and mixtures (see Section 3.1), it is necessary to verify (with experimental tests) whether the six fluids are thermally stable up to the optimized turbine inlet temperatures.

\subsection{Results for the HT-MEC scenario}

The exergy efficiency of the optimized ORC systems (as defined in Eq. (5)) is plotted in Fig. 5 as a function of the ratio between the critical temperature of the fluid $T_{C R}$ and the exhaust temperature of the engine $T_{F G}$ (where both temperatures are measured in Kelvin). Results indicate that the best three pure fluids are cyclopentane, ammonia and HCFO-1233zde (see Table 8) while the best mixtures are cyclopentane/cis-butene $(0.82 / 0.18)$, cyclopentane/heptane $(0.78 / 0.22)$, and ammonia/water (0.98/0.02) (see Table 9). Here the working fluids achieving the highest efficiency feature a $T_{C R} / T_{F C}$ ratio in over a wider range, between 0.65 and 0.82 .

Cyclopentane, ammonia, and HCFO-1233zde are the best pure fluids for the HT-MEC scenarios. The first two are flammable and toxic, thus less attractive from a safety point of view. While cyclopentane is an isentropic fluid, ammonia has a wet expansion, and then the vapor fraction at the turbine outlet can be an issue. In these cases, the optimal cycle for the ammonia and HCFO-1233zde is supercritical, while the one for cyclopentane is sub-critical. The difference in ORC power output between the three fluids is only 37 $\mathrm{kW}$, corresponding to a $1.09 \%$ difference of ORC power output, and negligible for the overall system (ICE + ORC). The higher ORC 


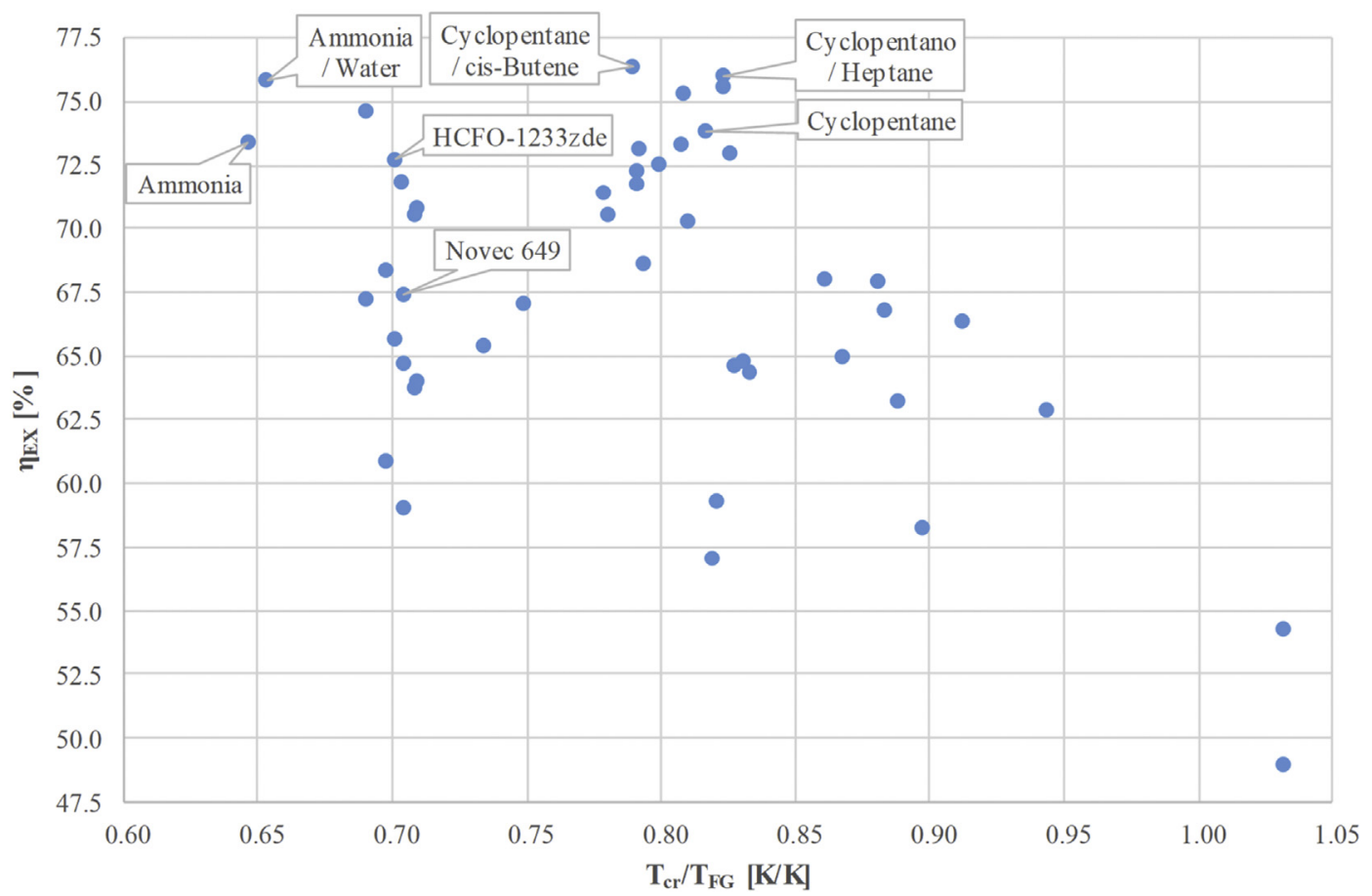

Fig. 5. Plot of the exergy efficiency as a function of the ratio between the critical temperature of the working fluid and the temperature of the flue gases made available by the engine for the HT-MEC scenario.

Table 8

Best pure fluids for HT-MEC scenario.

\begin{tabular}{|c|c|c|c|c|}
\hline & \multirow{2}{*}{$\begin{array}{l}\text { Unit of } \\
\text { measurement }\end{array}$} & \multicolumn{3}{|c|}{ HT-MEC - Pure fluids } \\
\hline & & Cyclopentane & Ammonia & HCFO-1233zde \\
\hline Heat transfer from ICE flue gases & - & Therm. oil loop & Therm. oil loop & Direct \\
\hline Working fluid mass flow rate & $\mathrm{kg} / \mathrm{s}$ & 14.84 & 5.04 & 28.82 \\
\hline Boiler pressure & bar & 42.70 & 166.93 & 43.56 \\
\hline Condensing pressure & bar & 0.62 & 13.16 & 1.69 \\
\hline Expander inlet temperature & ${ }^{\circ} \mathrm{C}$ & 235.54 & 325.00 & 256.34 \\
\hline Expander pressure ratio & - & 69.09 & 12.68 & 25.80 \\
\hline$\Delta \mathrm{h}$ expander & $\mathrm{kJ} / \mathrm{kg}$ & 171.59 & 511.93 & 87.49 \\
\hline Expander volumetric ratio & - & 107.03 & 7.61 & 25.75 \\
\hline Estimated expander number of stages & - & 2 & 4 & 2 \\
\hline Net ORC power & $\mathrm{kW}$ & 2456.5 & 2443.1 & 2420.2 \\
\hline$\eta_{\mathrm{MEC}, \mathrm{ORC}}$ & $\%$ & 23.76 & 23.63 & 23.41 \\
\hline$\eta_{\mathrm{EX}, \mathrm{ORC}}$ & $\%$ & 73.82 & 73.42 & 72.73 \\
\hline$\eta_{\mathrm{MEC}, \mathrm{ICE}+\mathrm{ORC}}$ & $\%$ & 56.13 & 56.07 & 55.97 \\
\hline
\end{tabular}

Table 9

Best mixtures for HT-MEC scenario.

\begin{tabular}{|c|c|c|c|c|}
\hline \multirow{3}{*}{$\begin{array}{l}\text { Compound } 1 \\
\text { Compound } 2\end{array}$} & \multirow{3}{*}{$\begin{array}{l}\text { Unit of } \\
\text { measurement }\end{array}$} & \multicolumn{3}{|c|}{ HT-MEC - Binary mixtures } \\
\hline & & \multirow{2}{*}{$\frac{\text { Cyclopentane }}{\text { cis-Butene }}$} & \multirow{2}{*}{$\frac{\text { Cyclopentane }}{\text { Heptane }}$} & \multirow{2}{*}{$\frac{\text { Ammonia }}{\text { Water }}$} \\
\hline & & & & \\
\hline Heat transfer from ICE flue gases & - & Therm. oil loop & Therm. oil loop & Therm. oil loop \\
\hline Mass fraction compound\#1 & - & 0.82 & 0.78 & 0.98 \\
\hline Mass fraction compound\#2 & - & 0.18 & 0.22 & 0.02 \\
\hline Working fluid mass flow rate & $\mathrm{kg} / \mathrm{s}$ & 14.87 & 14.28 & 5.14 \\
\hline Boiler pressure & bar & 47.04 & 36.44 & 165.34 \\
\hline Condensing pressure & bar & 0.76 & 0.37 & 11.41 \\
\hline Expander inlet temperature & ${ }^{\circ} \mathrm{C}$ & 233.78 & 235.26 & 324.86 \\
\hline Expander pressure ratio & - & 61.73 & 97.31 & 14.49 \\
\hline$\Delta \mathrm{h}$ expander & $\mathrm{kJ} / \mathrm{kg}$ & 177.56 & 182.37 & 519.80 \\
\hline Expander volumetric ratio & - & 83.91 & 146.15 & 8.51 \\
\hline Estimated expander number of stages & - & 2 & 2 & 4 \\
\hline Net ORC power & $\mathrm{kW}$ & 2540.4 & 2528.9 & 2523.2 \\
\hline$\eta_{\mathrm{MEC}, \mathrm{ORC}}$ & $\%$ & 24.58 & 24.46 & 24.41 \\
\hline$\eta_{\mathrm{EX}, \mathrm{ORC}}$ & $\%$ & 76.35 & 76.00 & 75.83 \\
\hline$\eta_{\mathrm{MEC}, \mathrm{ICE}+\mathrm{ORC}}$ & $\%$ & 56.50 & 56.45 & 56.43 \\
\hline
\end{tabular}


power output and net mechanical efficiency compared to the Man engine is a direct consequence of the higher temperature of the ICE flue gases. The three optimized cycles feature quite different parameters, as shown in Table 8. Cyclopentane has an evaporating pressure below the critical one while HCFO-1233zde and ammonia have supercritical cycles. Ammonia is also penalized by the excessively high value of optimal boiler pressure (167 bar), which considerably increase the cost of the boiler tubes, and the large turbine enthalpy drop $(512 \mathrm{~kJ} / \mathrm{kg}$ ), which requires at least four axial turbine stages. The other two fluids have moderate boiler pressures and require two turbine stages.

Fig. 6 (A) Shows that the optimal cycle for cyclopentane closely approximates the ideal Lorentz cycle. The composite curve of Fig. 6
(C) indicates that the heat integration with the hot and cold streams is very efficient, with close-to-minimum temperature differences between $220^{\circ} \mathrm{C}$ and $100^{\circ} \mathrm{C}$.

Among the pure fluids, the full result tables in the supplementary online material, indicate that very good performances are achieved also by HFE-245fa2, HFO-1366mzz (with a mechanical ORC efficiency only 1 percentage point lower than the maximum achieved by cyclopentane).

For the HT-MEC case, the best mixtures are all flammable: cyclopentane/cis-butene (0.82/0.18), cyclopentane/heptane $(0.78 /$ 0.22 ), and ammonia/water $(0.98 / 0.02)$. The maximum power output is around $2530 \mathrm{~kW}$, which corresponds to an overall ICE + ORC exergy efficiency of 56.46\%. The optimal cycle
A)

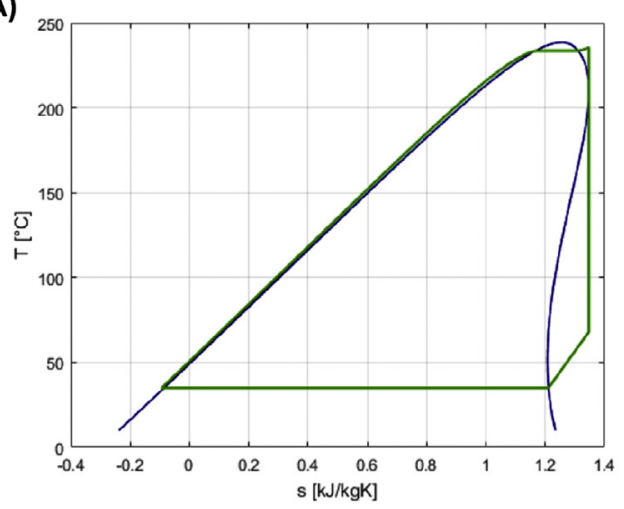

B)

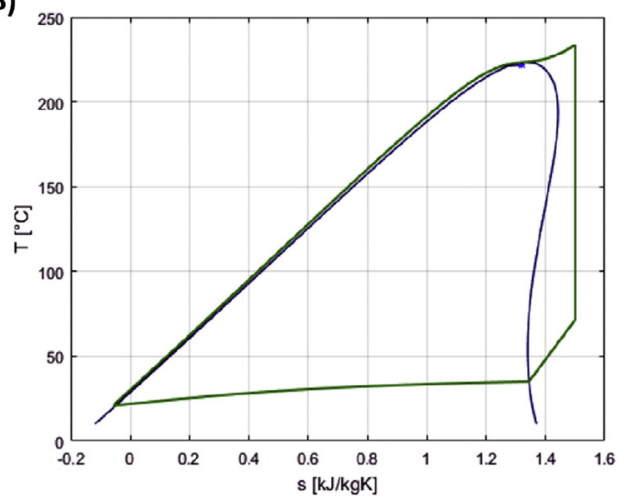

C)

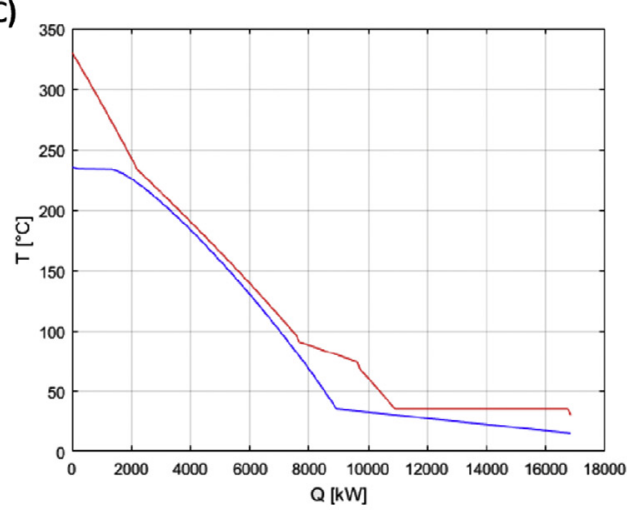

D)

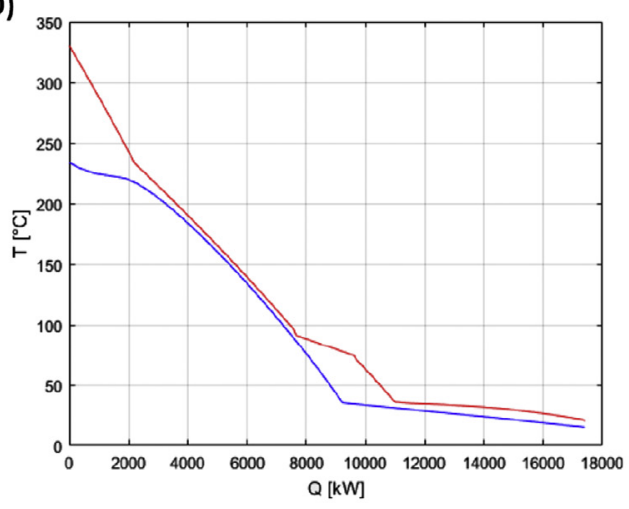

E)

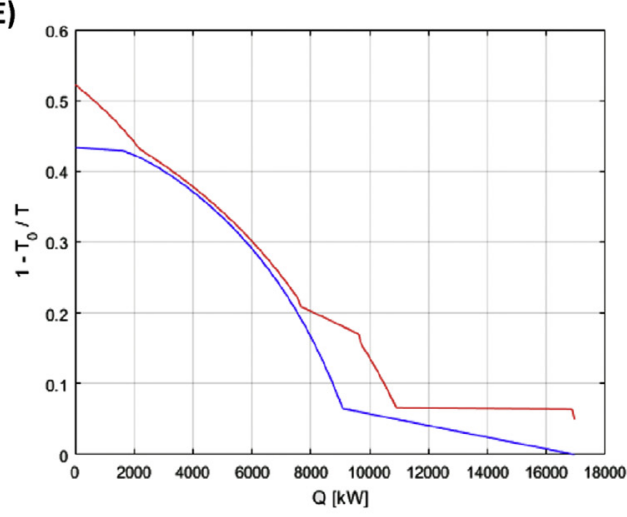

F)

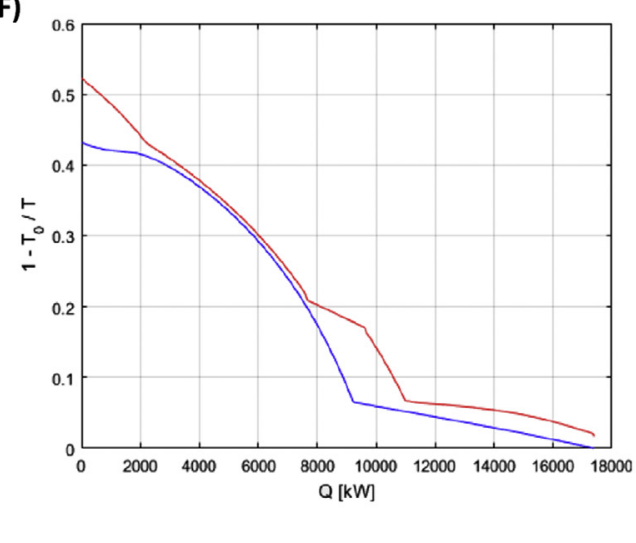

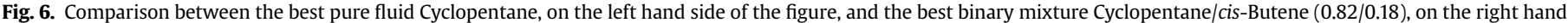

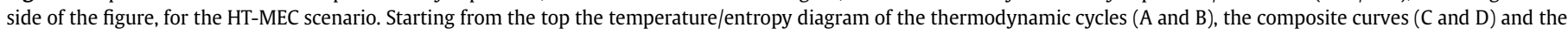
Carnot curves ( $\mathrm{E}$ and $\mathrm{F}$ ) of the heat transfer processes. 
configuration is supercritical for cyclopentane/cis-butene and ammonia/water and sub-critical for cyclopentane/heptane. The performance improvement of mixtures compared to the pure fluids, about 0.82 percentage points of mechanical efficiency of the ORC system and 0.37 of the ICE + ORC overall system, is mainly due to the lower heat transfer irreversibility in the condenser (better heat transfer matching between the condensing vapor and the cooling water).

It has to be noticed that for the best mixtures the mixing parameters available in REFPROP were not experimentally calibrated but estimated with the predictive method described in Ref. [46]. Thus, the performance results obtained for these mixtures may be affected by the inaccuracy of the equation of states.

As far as thermal stability is concerned, since data for HCFO- 1233zde were not found in the literature (see Section 3.1), an experimental test campaign should be performed to verify whether it suffers decomposition phenomena at the optimized turbine inlet temperature $\left(256^{\circ} \mathrm{C}\right)$.

\subsection{Results for the LT-CHP scenario}

The plot of the exergy efficiency as a function of the $T_{C R} / T_{F G}$ indicates that the working fluids achieving the highest efficiency are essentially those found for the LT-MEC case (featuring $T_{C R} / T_{F G}$ in the range $0.77-0.86$ ) (see Fig. 7).

The best pure fluid in terms of exergy efficiency is HFE-245cb2 with an optimized ORC, which generates approximately $1 \mathrm{MW}$ of mechanical power and 7.5 MW of thermal power (see Table 10). As

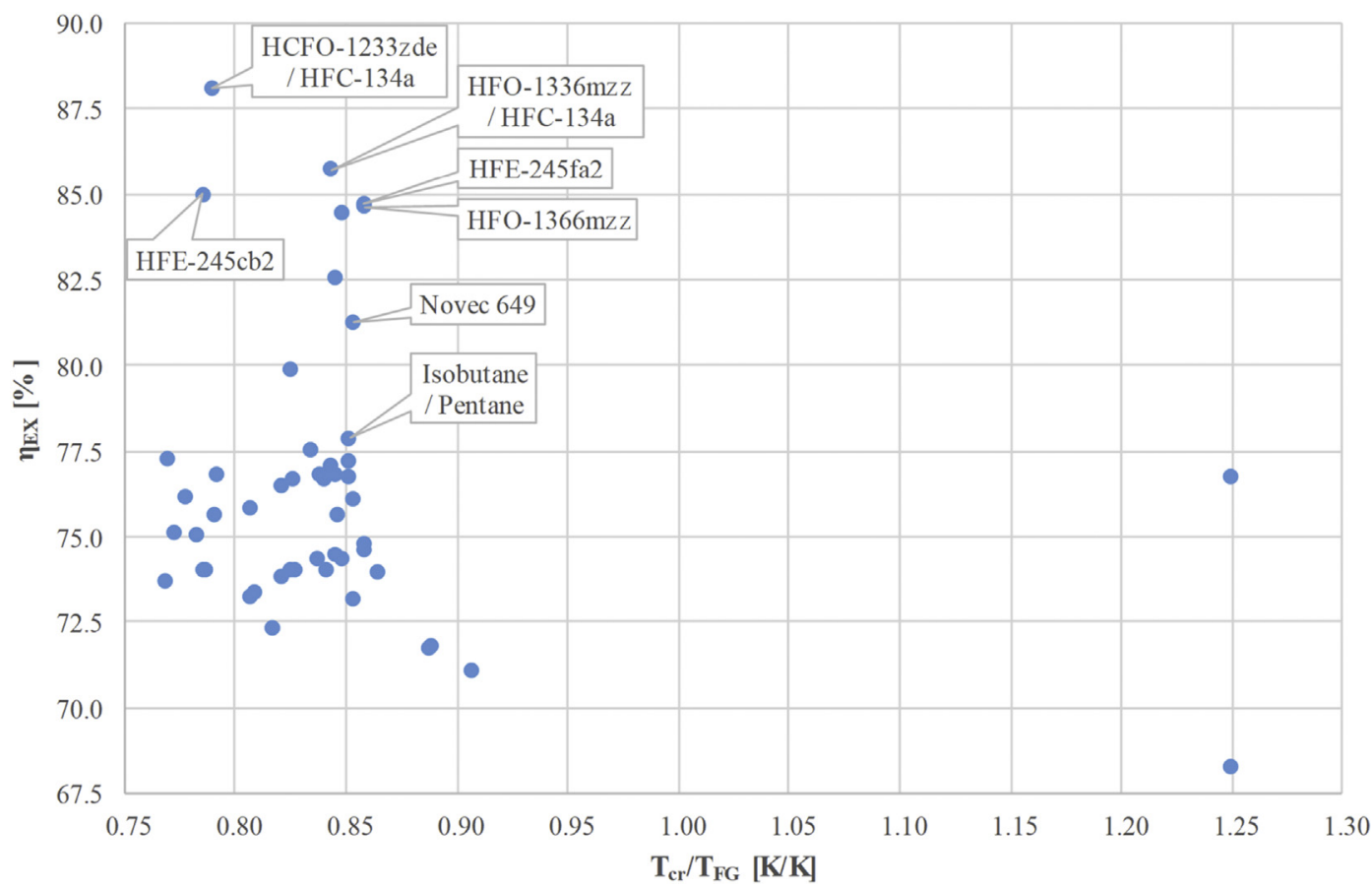

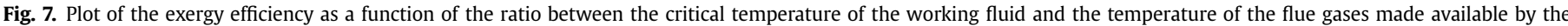
engine for the LT-CHP scenario.

Table 10

Best pure fluids for LT-CHP scenario.

\begin{tabular}{|c|c|c|c|c|}
\hline & \multirow{2}{*}{$\begin{array}{l}\text { Unit of } \\
\text { measurement }\end{array}$} & \multicolumn{3}{|c|}{ LT-CHP - Pure fluids } \\
\hline & & HFE-245cb2 & HFE-245fa2 & HFO-1366mzz \\
\hline Heat transfer from ICE flue gases & - & Direct & Direct & Direct \\
\hline Working fluid mass flow rate & $\mathrm{kg} / \mathrm{s}$ & 38.66 & 32.46 & 35.63 \\
\hline Boiler pressure & bar & 34.87 & 35.33 & 29.77 \\
\hline Condensing pressure & bar & 9.72 & 5.36 & 4.59 \\
\hline Expander inlet temperature & ${ }^{\circ} \mathrm{C}$ & 219.61 & 185.71 & 183.94 \\
\hline Expander pressure ratio & - & 3.59 & 6.59 & 6.48 \\
\hline$\Delta \mathrm{h}$ expander & $\mathrm{kJ} / \mathrm{kg}$ & 28.44 & 33.28 & 30.09 \\
\hline Expander volumetric ratio & - & 3.92 & 9.59 & 9.40 \\
\hline Estimated expander number of stages & - & 1 & 1 & 1 \\
\hline Net ORC power & $\mathrm{kW}$ & 1008.4 & 1000.0 & 996.5 \\
\hline Hot water loop mass flow rate & $\mathrm{kg} / \mathrm{s}$ & 89.25 & 89.35 & 89.40 \\
\hline Thermal power to heat user & $\mathrm{kW}$ & 7478.8 & 7487.2 & 7490.7 \\
\hline$\eta_{M E C, O R C}$ & $\%$ & 11.12 & 11.03 & 10.99 \\
\hline$\eta_{\mathrm{TH}, \mathrm{ORC}}$ & $\%$ & 82.48 & 82.58 & 82.62 \\
\hline$\eta_{\mathrm{EX}, \mathrm{ORC}}$ & $\%$ & 85.00 & 84.74 & 84.63 \\
\hline$\eta_{\mathrm{MEC}, \mathrm{ICE}+\mathrm{ORC}}$ & $\%$ & 54.50 & 54.46 & 54.44 \\
\hline$\eta_{\mathrm{TH}, \mathrm{ICE}+\mathrm{ORC}}$ & $\%$ & 36.36 & 36.40 & 36.42 \\
\hline$\eta_{\mathrm{EX}, \mathrm{ICE}+\mathrm{ORC}}$ & $\%$ & 60.58 & 60.55 & 60.53 \\
\hline
\end{tabular}


shown in Fig. 8 (A), this is a dry working fluid featuring a supercritical back-pressure cycle (i.e., condensation occurs at about $80^{\circ} \mathrm{C}$ and the condensation heat is given to the hot water loop for the thermal user). Adopting the back-pressure configuration of the ORC is thermodynamically advantageous because the condensation heat is not wasted but given to the heat user. Compared to the LTMEC case, another important peculiarity is the very high turbine outlet temperature leading to a large availability of desuperheating heat for the regenerator and the hot water loop (see Fig. 8).

HFE-245fa2, HFO-1366mzz, HCFO-1233zde, HFE-347mcc and Novec 649 reach very similar cycle performance indexes (exergy, mechanical and thermal efficiency are very close each other, see the supplementary online material) indicating that the best fluid should be selected on the basis of a more detailed techno-economic assessment and environmental criteria.

The best binary mixtures for LT-CHP case turn out to the same as the LT-MEC case, with differences in the optimal composition and cycle variables (see Table 11). Among these, the mixture HCFO-1233zde/HFC-134a (with mass fraction respectively of 0.59 and 0.41 ) reaches the higher exergy and mechanical efficiency. The cycle, represented in Fig. 8 (B), is very similar to that of the best pure fluid with the difference of the considerable temperature glide in condensation. Such glide reduces the exergy loss in the condenser due to the heat transfer process between condensing fluid and hot water for the heat user. Compared to the best pure
A)

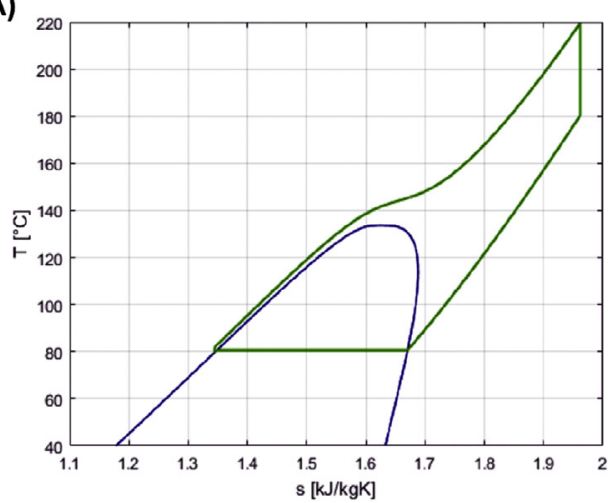

B)

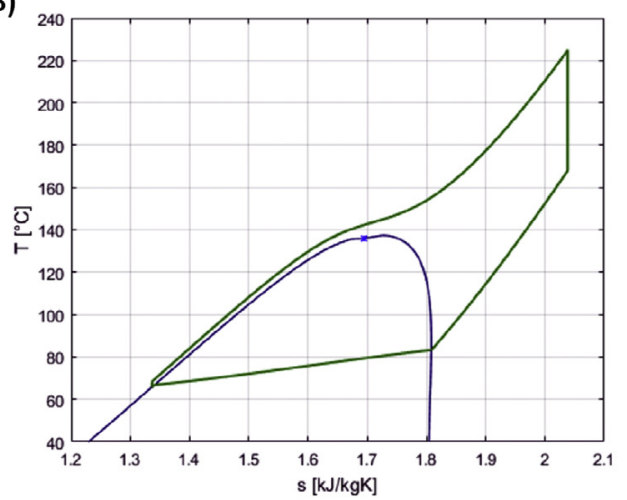

C)

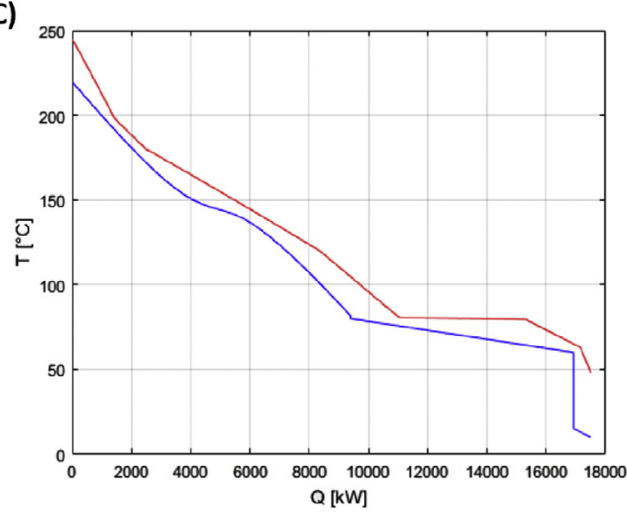

D)

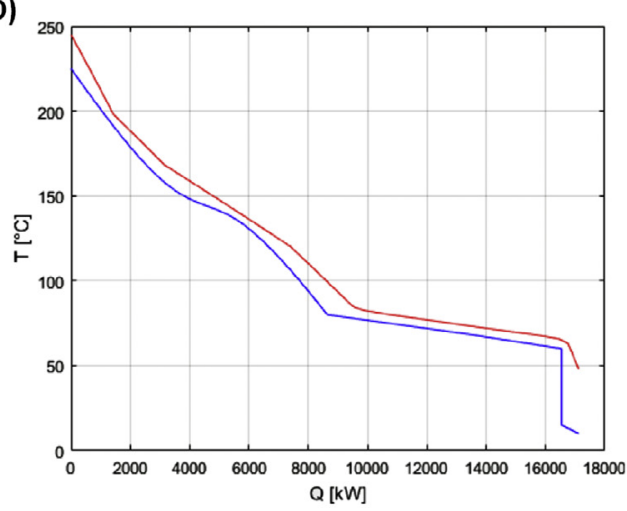

E)

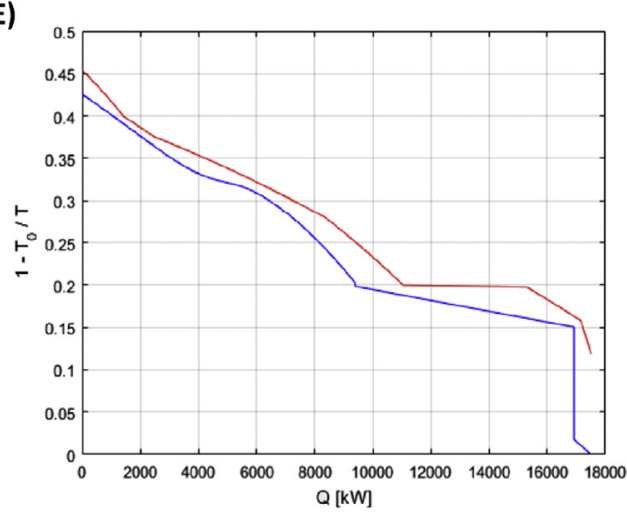

F)

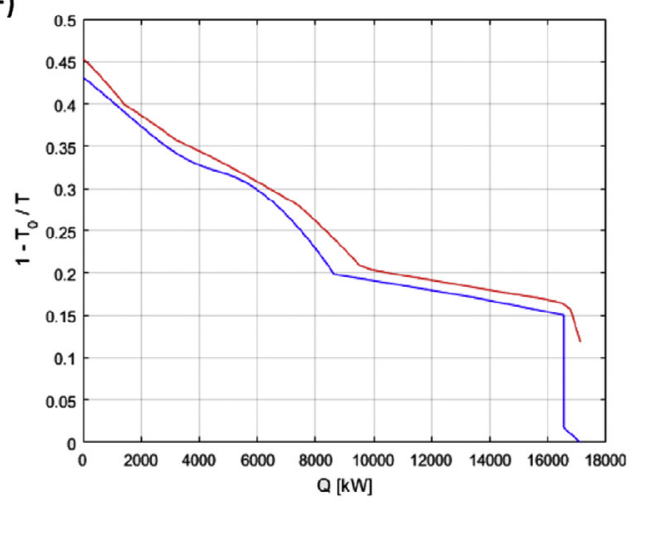

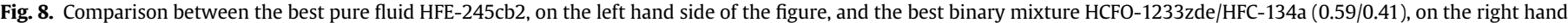

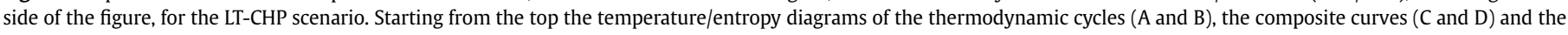
Carnot curves ( $\mathrm{E}$ and $\mathrm{F}$ ) of the heat transfer process. 


\begin{tabular}{|c|c|c|c|c|}
\hline \multirow[b]{2}{*}{ Compound 1} & \multirow{3}{*}{$\begin{array}{l}\text { Unit of } \\
\text { measurement }\end{array}$} & \multicolumn{3}{|c|}{ LT-CHP - Binary mixtures } \\
\hline & & \multirow{2}{*}{$\frac{\text { HCFO-1233zde }}{\text { HFC-134a }}$} & \multirow{2}{*}{$\frac{\text { HFO-1336mzz }}{\text { HFC-134a }}$} & \multirow{2}{*}{$\frac{\text { Isobutane }}{\text { Pentane }}$} \\
\hline Compound 2 & & & & \\
\hline Heat transfer from ICE flue gases & - & Direct & Direct & Therm. oil loop \\
\hline Mass fraction compound\#1 & - & 0.59 & 0.93 & 0.49 \\
\hline Mass fraction compound\#2 & - & 0.41 & 0.07 & 0.51 \\
\hline Working fluid mass flow rate & $\mathrm{kg} / \mathrm{s}$ & 31.49 & 35.75 & 15.71 \\
\hline Boiler pressure & bar & 47.16 & 32.09 & 38.48 \\
\hline Condensing pressure & bar & 12.16 & 5.19 & 6.97 \\
\hline Expander inlet temperature & ${ }^{\circ} \mathrm{C}$ & 224.94 & 183.99 & 174.03 \\
\hline Expander pressure ratio & - & 3.88 & 6.18 & 5.52 \\
\hline$\Delta \mathrm{h}$ expander & $\mathrm{kJ} / \mathrm{kg}$ & 38.39 & 31.09 & 61.94 \\
\hline Expander volumetric ratio & - & 3.99 & 8.40 & 8.89 \\
\hline Estimated expander number of stages & - & 1 & 1 & 1 \\
\hline Net ORC power & $\mathrm{kW}$ & 1108.0 & 1032.2 & 878.3 \\
\hline Hot water loop mass flow rate & $\mathrm{kg} / \mathrm{s}$ & 88.06 & 88.97 & 84.99 \\
\hline Thermal power to heat user & $\mathrm{kW}$ & 7379.2 & 7455.0 & 7121.4 \\
\hline$\eta_{M E C, O R C}$ & $\%$ & 12.22 & 11.38 & 9.69 \\
\hline$\eta_{\mathrm{TH}, \mathrm{ORC}}$ & $\%$ & 81.39 & 82.22 & 78.54 \\
\hline$\eta_{\text {EX,ORC }}$ & $\%$ & 88.12 & 85.75 & 77.86 \\
\hline$\eta_{\mathrm{MEC}, \mathrm{ICE}+\mathrm{ORC}}$ & $\%$ & 54.98 & 54.61 & 53.86 \\
\hline$\eta_{\mathrm{TH}, \mathrm{ICE}+\mathrm{ORC}}$ & $\%$ & 35.88 & 36.25 & 34.63 \\
\hline$\eta_{\text {EX,ICE }+ \text { ORC }}$ & $\%$ & 60.99 & 60.68 & 59.66 \\
\hline
\end{tabular}

fluid, the HCFO-1233zde/HFC-134a mixture achieves a 10\% higher mechanical power output (approximately $1.1 \mathrm{MW}$ ) resulting in an increase of net mechanical efficiency of the ORC equal to 1.1 percentage points. The thermal power provided to the heat user is essentially similar (lower) to that generated by the cycle with the best pure fluid. It has to be noticed that for the best refrigerant mixtures the mixing parameters available in REFPROP were not experimentally calibrated but estimated with the predictive method described in Ref. [46]. Thus, the performance results obtained for these mixtures may be affected by the inaccuracy of the equation of states.

The second best binary mixture, HFO-1336mzz/HFC-134a, features a similar optimal composition as the LT-MEC scenario, and it reaches mechanical and thermal efficiencies close to HCFO-1233zde/HFC-134a. On the contrary, the third best mixture (isobutane/pentane) achieves performance appreciably lower (even lower than the best pure fluids). The main reason is the need of adopting an indirect heat transfer solution (i.e., a thermal oil loop) between the flue gases and the ORC due to the flammability of the mixture.

For all three best mixtures, the turbine design can employ a single stage, like the best pure fluid, with a considerable technoeconomic advantage.

Although the optimized fluid superheating temperatures are rather low $\left(180-220^{\circ} \mathrm{C}\right)$, since no data were found in the literature for the three best pure fluids and mixtures (see Section 3.1), it is necessary to verify (with experimental tests) whether the six fluids are thermally stable up to the optimized turbine inlet temperatures.

\subsection{Results for the HT-CHP scenario}

The plot of the exergy efficiency as a function of the $T_{C R} / T_{F G}$ indicates that the pure fluids achieving the highest efficiency are essentially those found for the HT-MEC case with $T_{C R} / T_{F G}$ in the range $0.65-0.82$, and namely, HCFO-1233zde, ammonia and cyclopentane (see Table 12, Fig. 9). The optimal cycle variables are similar to the HT-MEC case with the difference of the higher condenser pressure, raised by the optimization algorithm to reproduce the back-pressure cycle configuration (i.e., provide the condensation heat to the hot water for the thermal user, as shown in the composite curves of Fig. 10 (C)). HCFO-1233zde appears to be the best option in terms of energy/exergy efficiency, safety-related issues, and turbine design (needing a single stage). The heat integration with the heat sources and heat sinks is quite good, as shown in the Carnot curves of Fig. 10 (E). On the other hand, its thermal stability up to $276{ }^{\circ} \mathrm{C}$ needs to be experimentally verified (see Section 3.1). Ammonia and cyclopentane, though the thermal oil loop (imposed by their flammability) introduces a thermodynamic penalty, can reach close-to-maximum exergy and mechanical effi-ciency of the ORC cycle. Among these two fluids, ammonia seems less promising that cyclopentane because of the very high boiler pressure (166 bar) and higher number of required turbine stages.

Fluids with good cycle performance are also Novec 649, HFE-347mcc and HFE-245fa2 (see the full results on the supplemen-tary online material).

The best mixtures use as basis HCFO-1233zde and cyclopentane (see Table 13). The mixtures of HCFO-1233zde/HFC-134a shows a very limited efficiency improvement (i.e., 0.12 percentage points of ORC mechanical efficiency) compared to the pure HCFO-1233zde. Indeed, the temperature glide in condensation is almost negligible, as shown in Fig. 10 (B). Instead, cyclopentane benefits from a significant performance improvement (approximately 5\% higher mechanical power production) when mixed with heptane or isooctane. However, also for these mixtures, results may be affected by the inaccuracy of the mixing parameters, which were estimated and not experimentally calibrated.

\section{Conclusions}

This paper addresses the optimal working fluid selection for organic Rankine cycle recovering heat from heavy-duty internal combustion engines. The analysis includes conventional as well as novel fluids with unknown or partially known thermodynamic properties with the aim of identifying the most promising ones to be considered in future experimental campaigns and engineering studies. Two heavy-duty internal combustion engines are considered: a two-stroke Diesel engine featuring a relatively low exhaust temperature (LT) and four-stroke engine featuring a higher exhaust 


\begin{tabular}{|c|c|c|c|c|}
\hline & \multirow{2}{*}{$\begin{array}{l}\text { Unit of } \\
\text { measurement }\end{array}$} & \multicolumn{3}{|c|}{ HT-CHP - Pure fluids } \\
\hline & & HCFO-1233zde & Ammonia & Cyclopentane \\
\hline Heat transfer from ICE flue gases & - & Direct & Therm. oil loop & Therm. oil loop \\
\hline Working fluid mass flow rate & $\mathrm{kg} / \mathrm{s}$ & 31.66 & 5.36 & 14.82 \\
\hline Boiler pressure & bar & 45.26 & 166.93 & 42.70 \\
\hline Condensing pressure & bar & 6.18 & 39.30 & 2.53 \\
\hline Expander inlet temperature & ${ }^{\circ} \mathrm{C}$ & 276.85 & 325.03 & 235.60 \\
\hline Expander pressure ratio & - & 7.33 & 4.25 & 16.85 \\
\hline$\Delta \mathrm{h}$ expander & $\mathrm{kJ} / \mathrm{kg}$ & 57.29 & 322.74 & 113.02 \\
\hline Expander volumetric ratio & - & 7.52 & 3.20 & 28.29 \\
\hline Estimated expander number of stages & - & 1 & 3 & 2 \\
\hline Net ORC power & $\mathrm{kW}$ & 1704.4 & 1598.0 & 1586.8 \\
\hline Hot water loop mass flow rate & $\mathrm{kg} / \mathrm{s}$ & 100.14 & 97.49 & 97.62 \\
\hline Thermal power to heat user & $\mathrm{kW}$ & 8391.2 & 8169.0 & 8180.1 \\
\hline$\eta_{\mathrm{MEC}, \mathrm{ORC}}$ & $\%$ & 16.49 & 15.46 & 15.35 \\
\hline$\eta_{\mathrm{TH}, \mathrm{ORC}}$ & $\%$ & 81.18 & 79.03 & 79.13 \\
\hline$\eta_{\text {EX,ORC }}$ & $\%$ & 85.90 & 81.93 & 81.67 \\
\hline$\eta_{\mathrm{MEC}, \mathrm{ICE}+\mathrm{ORC}}$ & $\%$ & 52.82 & 52.36 & 52.31 \\
\hline$\eta_{\mathrm{TH}, \mathrm{ICE}+\mathrm{ORC}}$ & $\%$ & 36.91 & 35.93 & 35.98 \\
\hline$\eta_{E X, I C E+O R C}$ & $\%$ & 59.00 & 58.37 & 58.33 \\
\hline
\end{tabular}

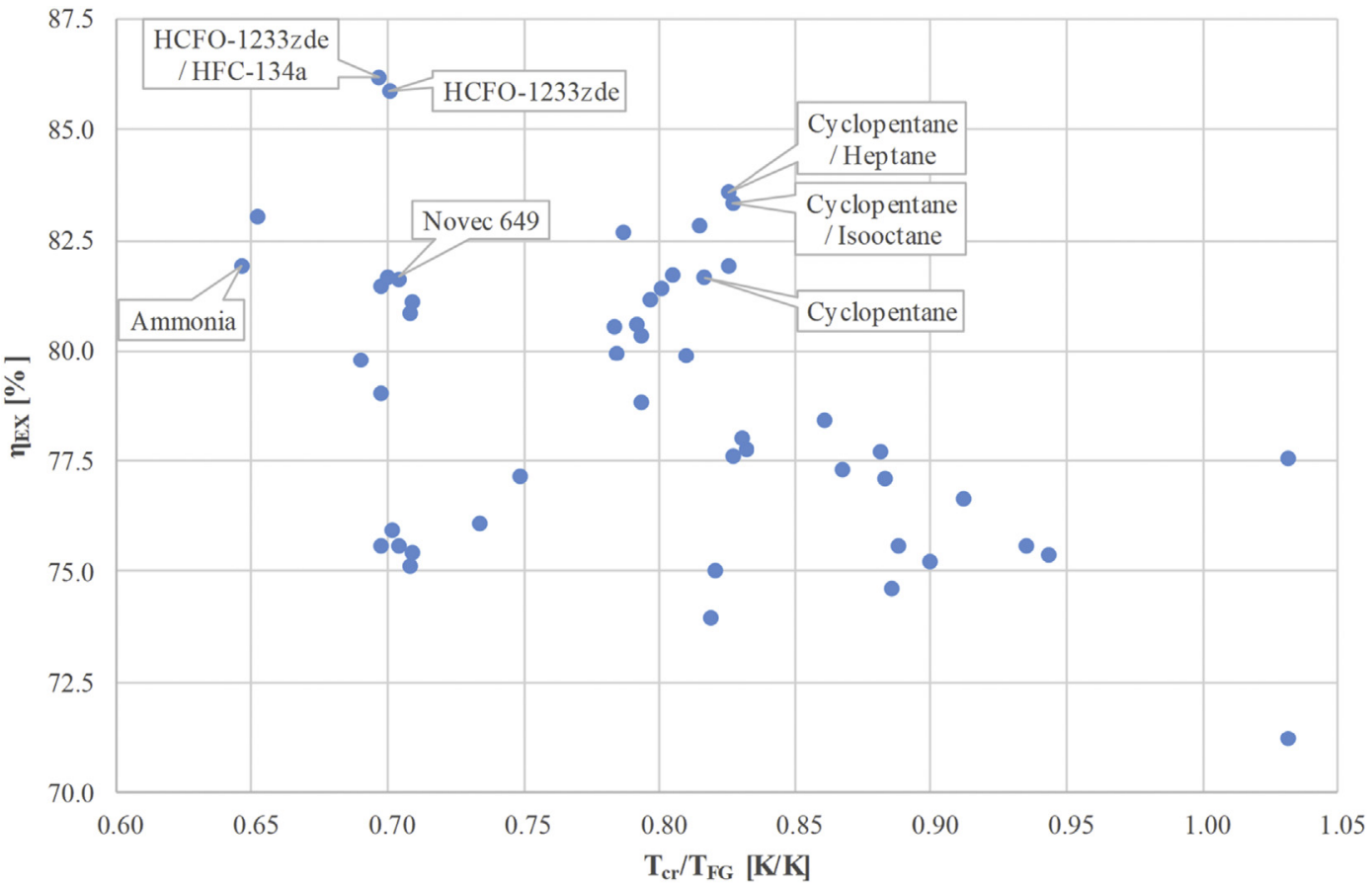

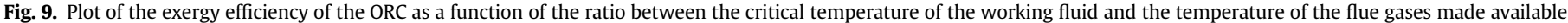
by the engine for the HT-CHP scenario.

temperature (HT). For both engines, two scenarios were considered: a scenario targeting the maximum recovery of mechanical power (MEC) and another one considering the cogeneration of thermal power (CHP). Since the objective of the work is to screen a large number of working fluids ( $>40$ for each application), the ideal Rankine cycle is considered in the assessment of the performance (i.e., isentropic pump and turbine, and heat exchangers without pressure drops and heat losses) so as to save computational time compared to more sophisticated models. Nevertheless, to perform a fair comparison between the different fluids, a computationally efficient cycle optimization approach determines the maximum achievable efficiency for each working fluid. The approach combines the evolutionary optimization algorithm PGS-COM with a rigorous heat integration methodology. The methodology is capable of optimizing not only the cycle but also the heat integration with the available heat sources/sinks as well as the composition of the working fluid (for mixture).

The best cycle configuration turns out to be the supercritical for all cases and almost all the best fluids. This result is not surprising since supercritical cycles can reach a better thermodynamic matching with the temperature profile of the hot engine flue gases (the T-s diagrams resemble the ideal Lorentz cycle). For all the CHP scenarios, the optimal ORC configuration is back-pressure. Another general result is that, for each engine, the same set of fluids results to be optimal for both the MEC and CHP scenarios. The main differences between the two scenarios are the optimal condensation pressure and superheating degree at turbine inlet (which are higher in the CHP scenario so as to provide the condensation and 
A)

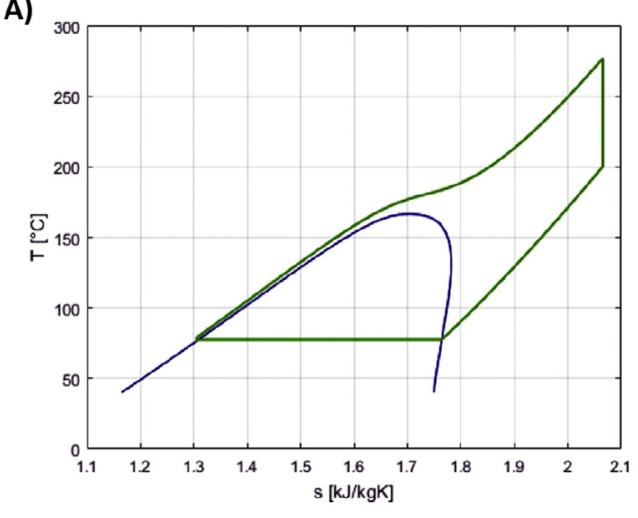

C)
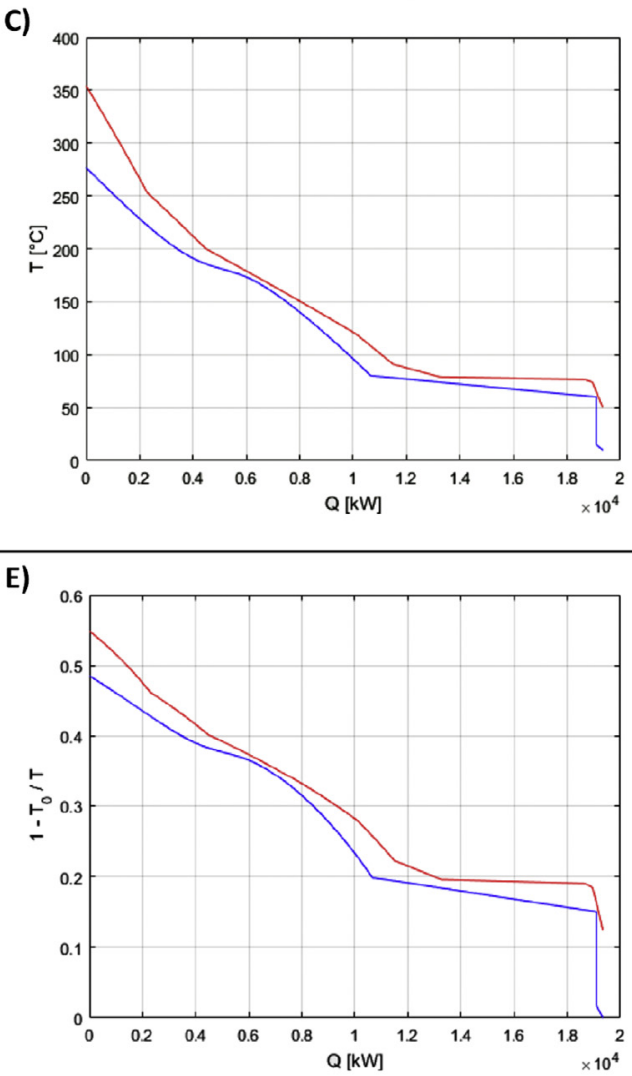

B)

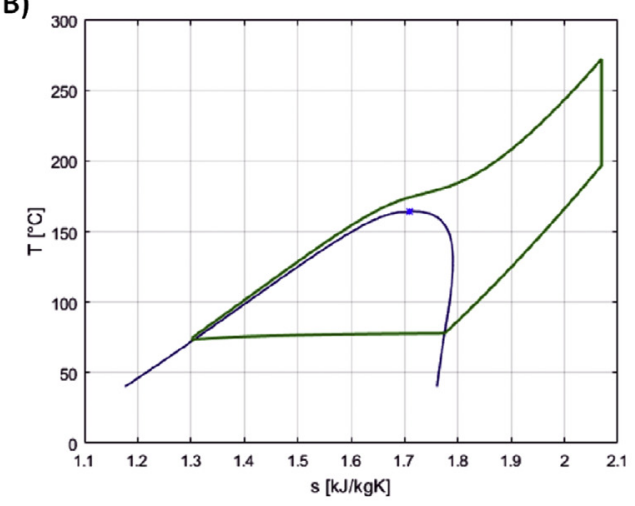

D)

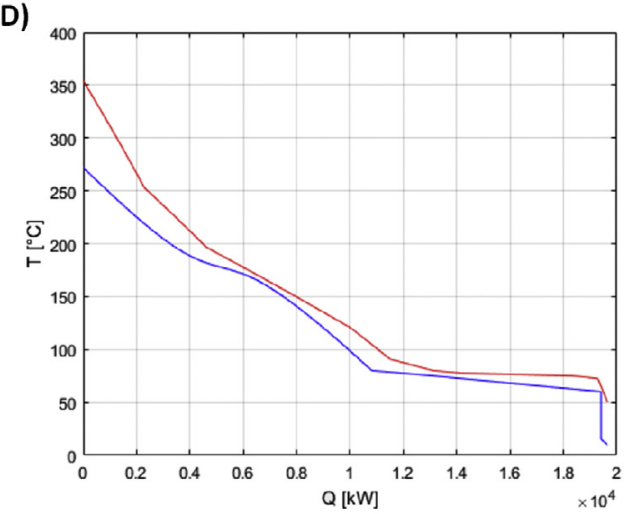

F)

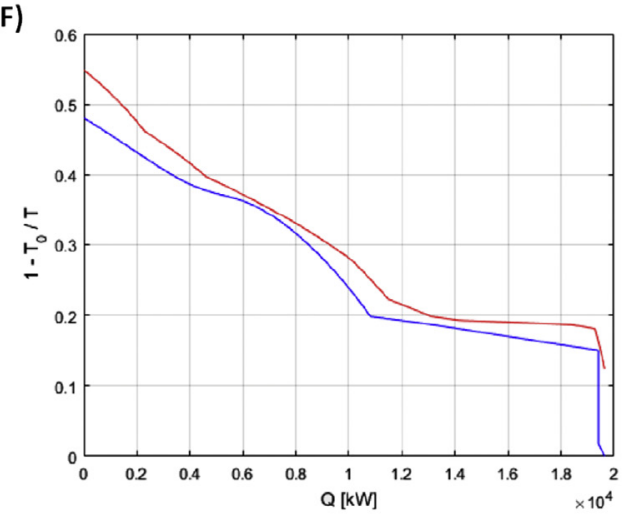

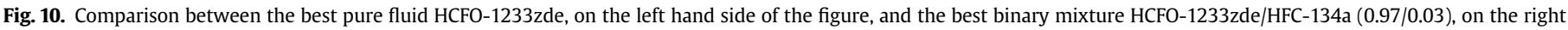

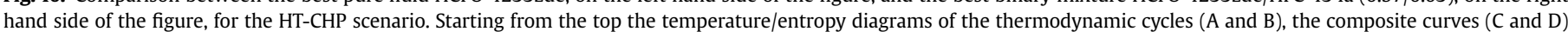
and the Carnot curves ( $\mathrm{E}$ and $\mathrm{F}$ ) of the heat transfer processes.

de-superheating heat to the thermal user).

For the engine with lower temperature exhaust gases (approximately $255^{\circ} \mathrm{C}$ ), HCFO-1233zde, HFE-245fa2, HFO-1336mzz, HFE$347 \mathrm{mcc}$, HFE-245cb2 and Novec 649 appear to be promising options. They feature a critical temperature in the range $77-86 \%$ of the engine flue gas temperature (with temperatures measured in $\mathrm{K})$. They all reach maximum or close-to-maximum ORC mechanical (18.6-19.9\%) efficiency with favorable cycle variables (pressures and temperatures). For the engine with higher temperature flue gases, the optimal working fluids are cyclopentane, ammonia, HCFO-1233zde, HFE-245fa2, HFO-1366mzz. Compared to the lower temperature engine case, these fluids feature a lower ratio between the critical temperature and the engine exhaust temperatures (in the range 65-82\%).

Since the novel refrigerants HCFO-1233zde, HFE-245fa2, HFE$347 \mathrm{mcc}$, HFE-245cb2 look very promising but their thermal stability limit is not known, future experimental works shall test their decomposition issues at the optimal operating temperatures found in this work (in the range $180-225^{\circ} \mathrm{C}$ ).

As far as mixtures are concerned, the use of optimized binary zeotropic blends leads to an increase of the mechanical ORC efficiency of around 0.72 percentage points in the LT-MEC case and 0.81 percentage points in the HT-MEC. The ORC power output increases by less than 3.7 percentage which turns out to be not appreciable compared to the ICE power output. In the cogeneration applications, mixtures lead to an ORC exergy efficiency gain of 3.12 
Table 13

Best mixtures for HT-CHP scenario.

\begin{tabular}{|c|c|c|c|c|}
\hline \multirow{3}{*}{$\begin{array}{l}\text { Compound } 1 \\
\text { Compound } 2\end{array}$} & \multirow{3}{*}{$\begin{array}{l}\text { Unit of } \\
\text { measurement }\end{array}$} & \multicolumn{3}{|c|}{ HT-CHP - Binary mixtures } \\
\hline & & \multirow{2}{*}{$\frac{\text { HCFO-1233zde }}{\text { HFC-134a }}$} & \multirow{2}{*}{$\frac{\text { Cyclopentane }}{\text { Heptane }}$} & \multirow{2}{*}{$\frac{\text { Cyclopentane }}{\text { Isooctane }}$} \\
\hline & & & & \\
\hline Heat transfer from ICE flue gases & - & Direct & Therm. oil loop & Therm. oil loop \\
\hline Mass fraction compound\#1 & - & 0.97 & 0.74 & 0.69 \\
\hline Mass fraction compound\#2 & - & 0.03 & 0.26 & 0.31 \\
\hline Working fluid mass flow rate & $\mathrm{kg} / \mathrm{s}$ & 32.66 & 14.04 & 14.31 \\
\hline Boiler pressure & bar & 45.31 & 38.55 & 38.03 \\
\hline Condensing pressure & bar & 6.45 & 1.57 & 1.52 \\
\hline Expander inlet temperature & ${ }^{\circ} \mathrm{C}$ & 271.99 & 242.21 & 243.87 \\
\hline Expander pressure ratio & - & 7.03 & 24.49 & 25.01 \\
\hline$\Delta \mathrm{h}$ expander & $\mathrm{kJ} / \mathrm{kg}$ & 55.98 & 124.55 & 121.44 \\
\hline Expander volumetric ratio & - & 7.21 & 42.57 & 45.02 \\
\hline Estimated expander number of stages & - & 1 & 2 & 2 \\
\hline Net ORC power & $\mathrm{kW}$ & 1716.7 & 1670.4 & 1659.7 \\
\hline Hot water loop mass flow rate & $\mathrm{kg} / \mathrm{s}$ & 99.99 & 96.63 & 96.75 \\
\hline Thermal power to heat user & $\mathrm{kW}$ & 8378.9 & 8096.6 & 8107.3 \\
\hline$\eta_{\mathrm{MEC}, \mathrm{ORC}}$ & $\%$ & 16.61 & 16.16 & 16.06 \\
\hline$\eta_{\mathrm{TH}, \mathrm{ORC}}$ & $\%$ & 81.06 & 78.33 & 78.43 \\
\hline$\eta_{\mathrm{EX}, \mathrm{ORC}}$ & $\%$ & 86.18 & 83.60 & 83.35 \\
\hline$\eta_{\mathrm{MEC}, \mathrm{ICE}+\mathrm{ORC}}$ & $\%$ & 52.88 & 52.67 & 52.63 \\
\hline$\eta_{\mathrm{TH}, \mathrm{ICE}+\mathrm{ORC}}$ & $\%$ & 36.86 & 35.61 & 35.66 \\
\hline$\eta_{\mathrm{EX}, \mathrm{ICE}+\mathrm{ORC}}$ & $\%$ & 59.05 & 58.63 & 58.60 \\
\hline
\end{tabular}

percentage points and 0.28 percentage points in the LT-CHP and HT-CHP cases respectively. Also in these cases, the increase in ORC mechanical power is limited compared to the engine size. Since the optimal cycle is supercritical, the temperature glide can be exploited only in condensation and, as a result, the advantage of mixtures compared to pure fluids is lower than the values reported in the literature. Although an accurate design of the heat exchangers would be necessary, this little efficiency advantage is likely not sufficient to compensate the reduction of heat transfer coefficient which affects mixtures [70].

\section{Appendix A. Supplementary data}

Supplementary data related to this article can be found at https://doi.org/10.1016/j.energy.2018.06.017.

\section{References}

[1] Kwak DH, Binns M, Kim JK. Integrated design and optimization of technologies for utilizing low grade heat in process industries. Appl Energy 2014;131: 307-22. https://doi.org/10.1016/j.apenergy.2014.06.037.

[2] Vaja I, Gambarotta A. Internal combustion engine (ICE) bottoming with organic rankine cycles (ORCs). Energy 2010;35:1084-93. https://doi.org/ 10.1016/j.energy.2009.06.001.

[3] Wang EH, Zhang HG, Fan BY, Ouyang MG, Yang FY, Yang K, et al. Parametric analysis of a dual-loop ORC system for waste heat recovery of a diesel engine. Appl Therm Eng 2014;67:168-78. https://doi.org/10.1016/j.applthermale ng.2014.03.023.

[4] Ma Z, Yang D, Guo Q. Conceptual design and performance analysis of an exhaust gas waste heat recovery system for a 10000TEU container ship. Pol Marit Res 2012;19:31-8. https://doi.org/10.2478/v10012-012-0012-8.

[5] Kalikatzarakis M, Frangopoulos CA. Multi-criteria selection and thermoeconomic optimization of an organic rankine cycle system for a marine application, vol. 18; 2015. p. 133-41. https://doi.org/10.5541/ijot.500007 5305.

[6] Larsen U, Sigthorsson O, Haglind F. A comparison of advanced heat recovery power cycles in a combined cycle for large ships. Energy 2014;74:260-8. https://doi.org/10.1016/j.energy.2014.06.096.

[7] Larsen U, Pierobon L, Haglind F, Gabrielii C. Design and optimisation of organic Rankine cycles for waste heat recovery in marine applications using the principles of natural selection. Energy 2013;55:803-12. https://doi.org/ 10.1016/j.energy.2013.03.021.

[8] Hung TC, Shai TY, Wang SK. A review of organic rankine cycles (ORCs) for the recovery of low-grade waste heat. Energy 1997;22:661-7. https://doi.org/ 10.1016/S0360-5442(96)00165-X

[9] Shu G, Li X, Tian H, Liang X, Wei H, Wang X. Alkanes as working fluids for hightemperature exhaust heat recovery of diesel engine using organic
Rankine cycle. Appl Energy 2014;119:204-17. https://doi.org/10.1016/ j.apenergy.2013.12.056.

[10] Roy JP, Misra A. Parametric optimization and performance analysis of a regenerative Organic Rankine Cycle using R-123 for waste heat recovery. Energy 2012;39:227-35. https://doi.org/10.1016/j.energy.2012.01.026.

[11] Di Battista D, Cipollone R, Villante C, Fornari C, Mauriello M. The potential of mixtures of pure fluids in ORC-based power units fed by exhaust gases in internal combustion engines. Energy Procedia 2016;101:1264-71. https:// doi.org/10.1016/j.egypro.2016.11.142.

[12] Shu G, Gao Y, Tian H, Wei H, Liang X. Study of mixtures based on hydrocarbons used in ORC (Organic Rankine Cycle) for engine waste heat recovery. Energy 2014;74:428-38. https://doi.org/10.1016/j.energy.2014.07.007.

[13] Wang EH, Zhang HG, Fan BY, Ouyang MG, Zhao Y, Mu QH. Study of working fluid selection of organic Rankine cycle (ORC) for engine waste heat recovery. Energy 2011;36:3406-18. https://doi.org/10.1016/j.energy.2011.03.041.

[14] Papadopoulos AI, Stijepovic M, Linke P. On the systematic design and selection of optimal working fluids for Organic Rankine Cycles. Appl Therm Eng 2010;30:760-9. https://doi.org/10.1016/j.applthermaleng.2009.12.006.

[15] Palma-Flores O, Flores-Tlacuahuac A, Canseco-Melchor G. Optimal molecular design of working fluids for sustainable low-temperature energy recovery. Comput Chem Eng 2015;72:334-49. https://doi.org/10.1016/ j.compchemeng.2014.04.009.

[16] Lampe M, Stavrou M, Bücker HM, Gross J, Bardow A. Simultaneous optimization of working fluid and process for organic rankine cycles using PC-SAFT. Ind Eng Chem Res 2014;53:8821-30. https://doi.org/10.1021/ie5006542.

[17] Linke P, Papadopoulos A, Seferlis P. Systematic methods for working fluid selection and the design, integration and control of organic rankine cycles-a review. Energies 2015;8:4755-801. https://doi.org/10.3390/en8064755.

[18] Astolfi M, Martelli E, Pierobon L. Thermodynamic and technoeconomic optimization of organic rankine cycle systems. Org. Rank. Cycle Power Syst. Elsevier; 2017. p. 173-249. https://doi.org/10.1016/ B978-0-08-100510-1.00007-7.

[19] Elsido C, Mian A, Martelli E. A systematic methodology for the technoeconomic optimization of Organic Rankine Cycles. In: IV int. Semin. ORC power syst. ORC2017, Milan, Italy; 2017.

[20] Yu H, Eason J, Biegler LT, Feng X. Simultaneous heat integration and technoeconomic optimization of Organic Rankine Cycle (ORC) for multiple waste heat stream recovery. Energy 2017;119:322-33. https://doi.org/10.1016/ j.energy.2016.12.061.

[21] MAN B\&W S60MC6 project guid. Man rep. 2009. http://engine.od.ua/ufiles/ MAN-S60mc6.pdf. [Accessed 19 February 2017].

[22] Wärtsilä 46DF product guide. Wärtsilä rep. 2016. http://cdn.wartsila.com/ docs/default-source/product-files/engines/df-engine/product-guide-o-ew46df.pdf?sfvrsn=9. [Accessed 19 February 2017].

[23] Martelli E, Capra F, Consonni S. Numerical optimization of combined heat and power organic rankine cycles - Part A: design optimization. Energy 2015;90: 310-28. https://doi.org/10.1016/j.energy.2015.06.111.

[24] Pini M, Persico G, Casati E, Dossena V. Preliminary design of a centrifugal turbine for organic rankine cycle applications. J Eng Gas Turbines Power 2013;135:42312. https://doi.org/10.1115/1.4023122.

[25] Capra F, Martelli E. Numerical optimization of combined heat and power Organic Rankine Cycles - Part B: simultaneous design \& part-load 
optimization. Energy 2015;90:329-43. https://doi.org/10.1016/j.energy.2015. 06.113.

[26] Kaya A, Lazova M, Bağcı Ö, Lecompte S, Ameel B, De Paepe M. Design sensitivity analysis of a plate-finned air-cooled condenser for low-temperature organic rankine cycles. Heat Tran Eng 2017;38:1018-33. https://doi.org/ 10.1080/01457632.2016.1216966.

[27] Walraven D, Laenen B, D'haeseleer W. Comparison of shell-and-tube with plate heat exchangers for the use in low-temperature organic Rankine cycles. Energy Convers Manag 2014;87:227-37. https://doi.org/10.1016/ j.enconman.2014.07.019.

[28] Lecompte S, Van den Broek M, De Paepe M. Optimal sizing of heat exchangers for organic rankine cycles (ORC) based on thermo-economics. In: Proc. 15th int. Heat transf. Conf., Connecticut: Begellhouse; 2014. p. 1-11. https:// doi.org/10.1615/IHTC15.rne.008989.

[29] Borel L, Favrat D. Thermodynamics and energy systems analysis: from energy to exergy. first ed. 2010.

[30] Macchi E, Astolfi M. Organic rankine cycle (ORC) power systems. Woodhead Publishing; 2016.

[31] Pasetti M, Invernizzi CM, Iora P. Thermal stability of working fluids for organic Rankine cycles: an improved survey method and experimental results for cyclopentane, isopentane and n -butane. Appl Therm Eng 2014;73:764-74. https://doi.org/10.1016/j.applthermaleng.2014.08.017.

[32] NIST website n.d. https://www.nist.gov/srd/refprop (accessed December 29, 2017).

[33] Lemmon EW, Huber ML. McLinden MO. NIST reference fluid thermodynamic and transport properties - REFPROP. 2013. NIST Stand Ref Database 23, Version 9.1. https://www.nist.gov/sites/default/files/documents/srd/REFPRO P9.PDF. [Accessed 29 December 2017].

[34] Lasala S, Invernizzi C, Iora P, Chiesa P, Macchi E. Thermal stability analysis of perfluorohexane. Energy Procedia 2015;75:1575-82. https://doi.org/10.1016/ j.egypro.2015.07.358.

[35] Zhao Z, Chaos M, Kazakov A, Dryer FL. Thermal decomposition reaction and a comprehensive kinetic model of dimethyl ether. Int J Chem Kinet 2008;40: 1-18. https://doi.org/10.1002/kin.20285.

[36] Leibowitz H, Mirolli MD. First Kalina combined cycle plant tested successfully. Power Eng May 1997:101.

[37] Invernizzi C, Pasini A. Thermodynamic performances of a new working fluid for power Rankine cycles. La Termotec 2000:87-92.

[38] Bombarda P, Invernizzi CM, Pasetti M. Stabilità termica di fluidi di lavoro e prestazioni termodinamiche del refrigerante HFC-245fa in cicli per applicazioni geotermiche. In: Atti Del $66^{\circ}$ Congr Naz ATI; 2011. p. 895-900.

[39] Invernizzi CM, Bonalumi D. Thermal stability of organic fluids for organic rankine cycle systems. Org. Rank. Cycle Power Syst. University of Brescia, Brescia, Italy: Elsevier; 2017. p. 121-51. https://doi.org/10.1016/ B978-0-08-100510-1.00005-3.

[40] 3M. $3 \mathrm{M}^{\mathrm{TM}}$ Novec $^{\mathrm{TM}} 649$ engineered fluid product information. 3M rep. 2009. http://multimedia.3m.com/mws/media/5698650/3mtm-novectm-649engineered-fluid.pdf. [Accessed 19 February 2017].

[41] Kontomaris KK. HFO-1336mzz-Z: high temperature chemical stability and Use as A Working fluid in organic rankine cycles. In: 15th int. Refrig. Air cond. Conf., west Lafayette, Indiana, USA; 2014. p. 1-10.

[42] Invernizzi CM, Iora P, Manzolini G, Lasala S. Thermal stability of $\mathrm{n}$-pentane, cyclo-pentane and toluene as working fluids in organic Rankine engines. Appl Therm Eng 2017;121:172-9. https://doi.org/10.1016/j.applthermaleng.2017. 04.038.

[43] Adams MC, Yamada Y, Yagi M, Kondo T, Wada T. Stability of methanol, propanol, and Sf 6 as high-temperature tracers. 2000. p. 3015-9.

[44] Angelino G, Invernizzi C. Cyclic methylsiloxanes as working fluids for space power cycles. J Sol Energy Eng 1993;115:130. https://doi.org/10.1115/ 1.2930039 .

[45] Bi S, Cui J, Zhao G, Wu J. Surface tension and liquid viscosity measurement for binary mixtures of R134a with R1234yf and R1234ze(E). Fluid Phase Equil 2016;414:60-4. https://doi.org/10.1016/j.fluid.2016.01.013.

[46] Lemmon EW, McLinden MO. Method for estimating mixture equation of state parameters. Thermophys. Prop. Transf. Process. New Refrig. Paderborn, Germany: International Institute of Refrigeration (IIR); 2001. p. 23-30.

[47] Gassner M, Maréchal F. Methodology for the optimal thermo-economic, multi-objective design of thermochemical fuel production from biomass. Comput Chem Eng 2009;33:769-81. https://doi.org/10.1016/j.compche meng.2008.09.017.

[48] Biegler LT, Grossmann IE, Westerberg AW. Systematic methods of chemical process design. first ed. Upper Saddle River, New Jersey 07458: Prentice Hall; 1997.

[49] Martelli E, Amaldi E. PGS-COM: a hybrid method for constrained non-smooth black-box optimization problems. Comput Chem Eng 2014;63:108-39. https://doi.org/10.1016/j.compchemeng.2013.12.014.

[50] MathWork website n.d. https://it.mathworks.com/products/matlab (accessed December 29, 2017).

[51] Maréchal F, Kalitventzeff B. Process integration: selection of the optima utility system. Comput Chem Eng 1998;22:S149-56. https://doi.org/10.1016/ S0098-1354(98)00049-0.

[52] Scaccabarozzi R, Gatti M, Martelli E. Thermodynamic analysis and numerical optimization of the NET Power oxy-combustion cycle. Appl Energy 2016;178 505-26. https://doi.org/10.1016/j.apenergy.2016.06.060.

[53] Digabel S Le, Wild SM. A taxonomy of constraints in simulation-based optimization. 2015. p. 1-21.

[54] Hu Xiaohui, Eberhart R. Solving constrained nonlinear optimization problems with particle swarm optimization. In: 6th World multiconference syst. Cybern. Informatics 2002, Orlando, Florida, USA; 2002.

[55] Lewis RM, Shepherd A, Torczon V. Implementing generating set search methods for linearly constrained minimization. SIAM J Sci Comput 2007;29: 2507-30. https://doi.org/10.1137/050635432.

[56] Box MJ. A new method of constrained optimization and a comparison with other methods. Comput J 1965;8:42-52. https://doi.org/10.1093/comjnl/ 8.1.42.

[57] Andersson J. Multiobjective optimization in engineering design: applications to fluid power systems. Linköpings universite; 2001.

[58] Nord LO, Martelli E, Bolland O. Weight and power optimization of steam bottoming cycle for offshore oil and gas installations. Energy 2014;76:891-8. https://doi.org/10.1016/j.energy.2014.08.090.

[59] Gatti M, Martelli E, Maréchal F, Consonni S. Multi-objective optimization of a Rectisol $®$ process. In: Klemeš JJ, Varbanov PS, Liew PY, editors. Comput. Aided chem. Eng, vol. 33; 2014. p. 1249-54. https://doi.org/10.1016/ B978-0-444-63455-9.50043-X.

[60] Gatti M, Martelli E, Maréchal F, Consonni S. Multi-Objective optimization of a selexol ${ }^{\circledR}$ process for the selective removal of $\mathrm{CO} 2$ and $\mathrm{H} 2 \mathrm{~S}$ from coal-derived syngas. In: ECOS 2015-28th int. Conf. Effic. Cost, Optim. Simul. Environ. Impact energy syst., international conference on efficiency, cost, optimization, simulation and environmental impact of energy systems; 2015.

[61] Mian A, Martelli E, Maréchal F. Framework for the multiperiod sequential synthesis of heat exchanger networks with selection, design, and scheduling of multiple utilities. Ind Eng Chem Res 2016;55:168-86. https://doi.org/ 10.1021/acs.iecr.5b02104.

[62] Elsido C, Bischi A, Silva P, Martelli E. Two-stage MINLP algorithm for the optimal synthesis and design of networks of CHP units. Energy 2017;121: 403-26. https://doi.org/10.1016/j.energy.2017.01.014.

[63] Magli F, Capra F, Bortoluzzi G, Martelli E, Gatti M. Multi-objective optimization of the water scrubbing process for biogas upgrading. 2017. p. 2551-6. https:// doi.org/10.1016/B978-0-444-63965-3.50427-X

[64] Ahmad S, Linnhoff B, Smith R. Cost optimum heat exchanger networks-2. targets and design for detailed capital cost models. Comput Chem Eng 1990;14:751-67. https://doi.org/10.1016/0098-1354(90)87084-3.

[65] Linnhoff $B$, Hindmarsh E. The pinch design method for heat exchanger networks. Chem Eng Sci 1983;38:745-63. https:// doi.org/10.1016/0009-2509(83)80185-7.

[66] Papoulias SA, Grossmann IE. A structural optimization approach in process synthesis-II: heat recovery networks. Comput Chem Eng 1983;7:707-21. https://doi.org/10.1016/0098-1354(83)85023-6.

[67] Zhang Y. Solving large-scale linear programs by interior-point methods under the Matlab * Environment $\dagger$. Optim Meth Software 1998;10:1-31. https:// doi.org/10.1080/10556789808805699.

[68] Macchi E, Perdichizzi A. Efficiency prediction for axial-flow turbines operating with nonconventional fluids. J Eng Power 1981;103:718. https://doi.org/ 10.1115/1.3230794.

[69] Marechal F, Favrat D. Combined exergy and pinch analysis for optimal energy conversion technologies integration. In: T G, H JE, G T, R A, K S, editors. 18th Int. Conf. Effic. Cost, Optim. Simulation, Environ. Impact Energy Syst. ECOS 2005, Laboratory for Industrial Energy Systems, Ecole Polytechnique Fédérale de Lausanne. Lausanne, Switzerland: Tapir Academic Press; 2005. p. 177-84.

[70] Jung DS, McLinden M, Radermacher R, Didion D. A study of flow boiling heat transfer with refrigerant mixtures. Int J Heat Mass Tran 1989;32:1751-64. https://doi.org/10.1016/0017-9310(89)90057-4. 